2. To: (Receiving Organization)

G. A. Meyer

Retrieval Programs

5. Proj./Prog./Dept./Div.: Waste Management

8. Originator Remarks:

Second transmittal for approval and release. Draft document review completed and comments incorporated.

11. Receiver Remarks:

\begin{tabular}{l|r} 
3. From: (originating organization) & 4. Related EDT No.: \\
Plant Systems Technical Basis & N/A \\
\hline $\begin{array}{l}\text { 6. Cog. Engr.: } \\
\text { D. F. Iwatate }\end{array}$ & $\begin{array}{r}\text { 7. Purchase order No.: } \\
\text { N/A }\end{array}$ \\
\hline
\end{tabular}

9. Equip./Component No.:

$$
N / A
$$

10. Systen/Bldg./Facility: $N / A$

12. Major Assm. DWg. No.: $N / A$

13. Permit/Permit Application No.: N/A

14. Required Response Date:

$N / A$

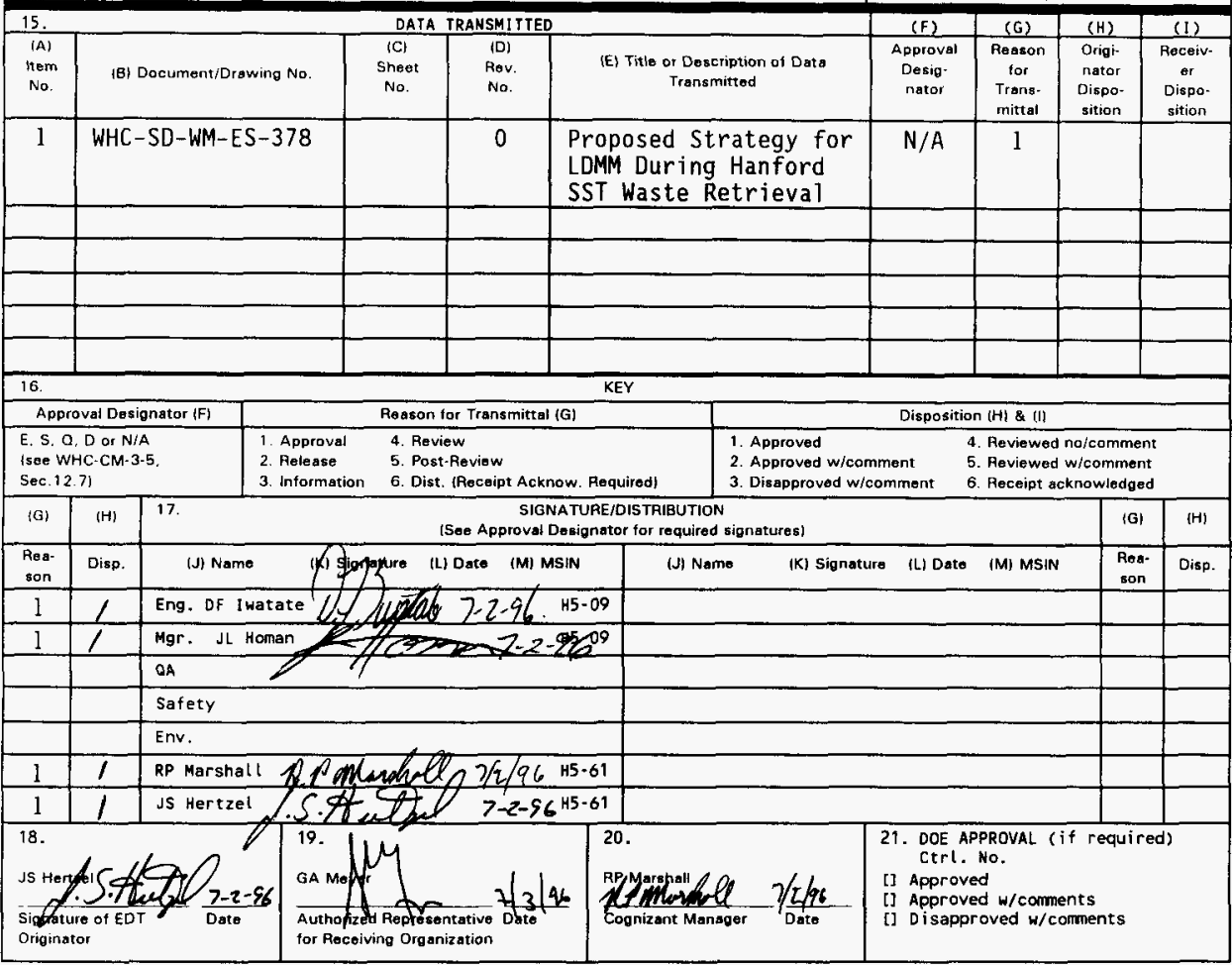

BD-7400-172-2(04/94) GEF097 


\section{Proposed Strategy for Leak Detection, Monitoring, and Mitigation (LDMM) During Hanford Single-Shell Tank Waste Retrieval}

\section{F. Iwatate}

Westinghouse Hanford Company, Richland, WA 99352

U.S. Department of Energy Contract DE-AC06-87RL10930

$\begin{array}{lll}\text { EDT/ECN: } & 606483 & \text { UC: } 721 \\ \text { Org Code: } & 73530 & \text { Charge Code: D2046 } \\ \text { B\&R Code: } & \text { EW3130010 } & \text { Tota7 Pages: 808 }\end{array}$

Key Words: Single-Shell Tanks, waste, leak, detection, monitoring, mitigation

Abstract:

This document proposes a strategy to address issues related to leakage from single-shell tanks (SSTS) during sluicing. A set of criteria are proposed to capture the relevant issues pertaining to leak detection, monitoring, and mitigation (LDMM), and allow DOE-RL, the Contractor, Ecology, and Hanford Stakeholders to reach concensus on allowable leakage volumes (ALVs). Technical studies and findings that support the proposed strategy, and ALV criteria, are summarized and referenced. This document specifically addresses LDMM for SSTs at Hanford, Washington.

TRADEMARK DISCLAIMER. Reference herein to any specific commercial product, process, or service by trade name, tradenark, manufacturer, or otherwise, does not necessarily constitute or imply its endorsement, recommendation, or favering by the United States Goverment or any agency thereof or its contractors or subcontractors.

Printed in the United States of Anerica. To obtain copies of this document, contact: WHC/BCS Document Control Services, P.O. Box 1970, Mailstop H6-08, Richland WA 99352, Phone (509) 372-2420; Fax (509) 376-4989.
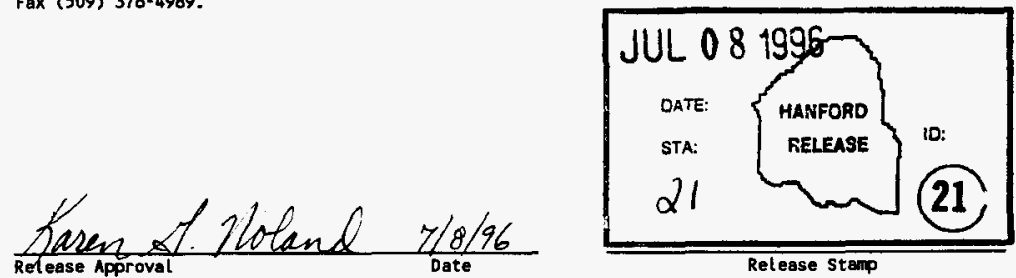


\title{
PROPOSED STRATEGY FOR LEAK DETECTION, MONITORING, AND MITIGATION DURING HANFORD SINGLE-SHELL TANK WASTE RETRIEVAL
}

\author{
(LDMM SUPPORT TO THE \\ INITIAL SINGLE-SHELL TANK RETRIEVAL SYSTEM \\ AND TRI-PARTY AGREEMENT MUESTONES)
}

June 28, 1996

\author{
Prepared by: \\ Deborah F. Iwatate (WHC)
}
With Assistance and Contribution from: Jeff S. Hertzel (WHC)

Edward A. Fredenburg (WHC)

Russell L. Treat (Foster Wheeler Environmental Corp.)

Brian B. Peters (Foster Wheeler Environmental Corp.)

Westinghouse Hanford Company 


\section{TABLE OF CONTENTS}

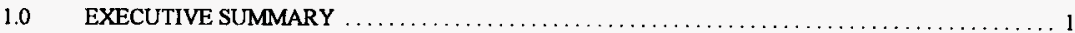

Table la: Allowable Leakage Criteria Related to Specific Tier and Decision Levels . . . . . . . . 4

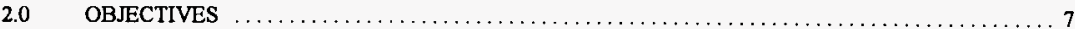

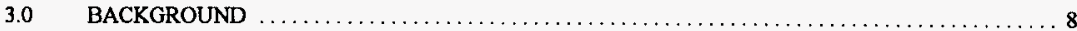

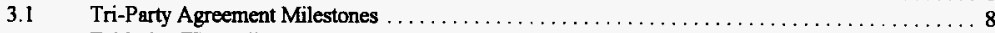

Table 3a: TPA Milestones Specifically Related to LDMM $\ldots \ldots \ldots \ldots \ldots \ldots \ldots \ldots \ldots \ldots$. 9

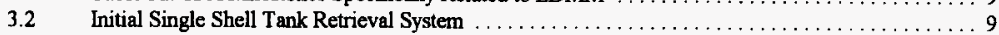

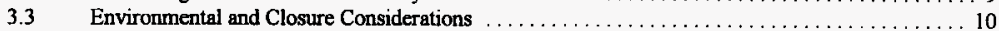

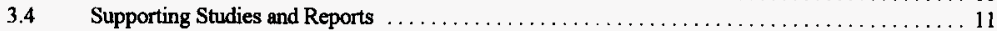

Table 3b: Summary Listing of LDMM Technical Basis Documents . . . . . . . . . . . . . . 11

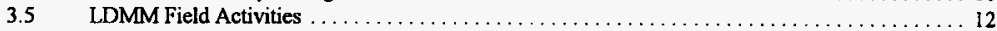

Table 3c: Summary of FY-94 through FY-97 Hanford LDMM Field Activities . . . . . . . . 13

$4.0 \quad$ STRATEGY TO DETERMINE ALLOWABLE LEAKAGE VOLUME $\ldots \ldots \ldots \ldots \ldots \ldots \ldots \ldots \ldots \ldots$

5.0 CRITERIA FOR DETERMINING ALLOWABLE LEAKAGE $\ldots \ldots \ldots \ldots \ldots \ldots \ldots \ldots \ldots \ldots \ldots$

Table 4a: Proposed Criteria for Deternining Allowable Leakage Volumes $\ldots \ldots \ldots \ldots \ldots \ldots$. 17

$5.1 \quad$ Major Leakage Boundaries Addressed by Leakage Criteria $\ldots \ldots \ldots \ldots \ldots \ldots \ldots \ldots \ldots \ldots \ldots$

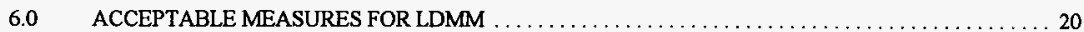

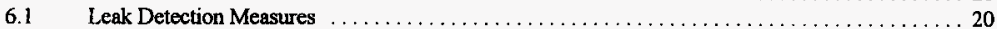

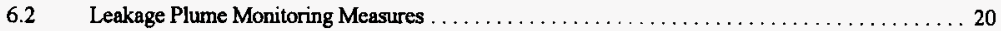

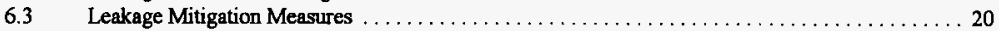

6.4 Incorporation of Future/Candidate LDMM Technologies into Retrieval Activities . . . . . . . 21

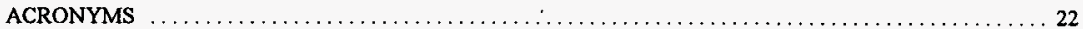

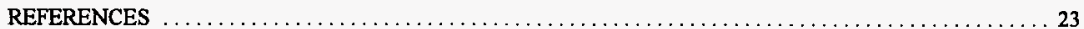


APPENDIX A: TERMINOLOGY AND DEFINITIONS RELATED TO LDMM $\ldots \ldots \ldots \ldots \ldots \ldots$

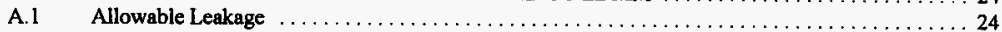

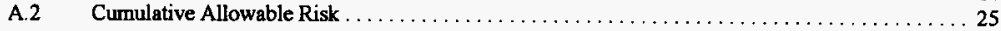

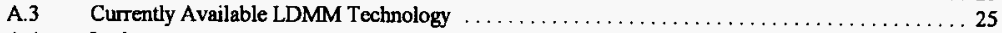

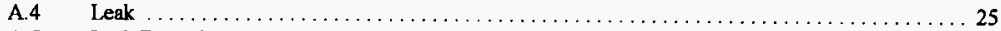

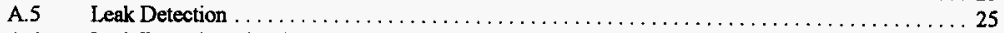

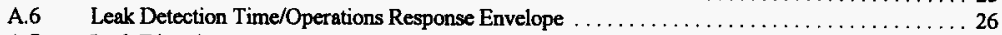

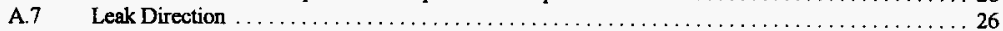

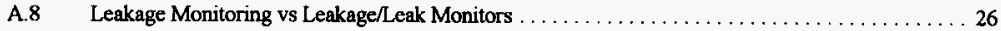

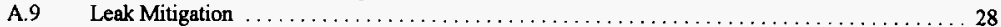

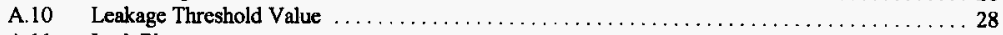

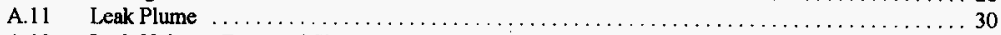

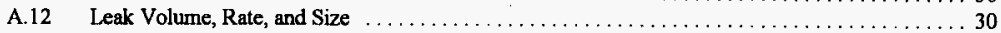

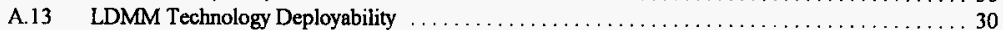

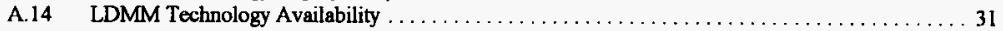

A.15 Minimum Practicable Achievable Leakage $\ldots \ldots \ldots \ldots \ldots \ldots \ldots \ldots \ldots \ldots \ldots \ldots \ldots \ldots \ldots$

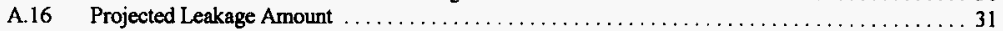

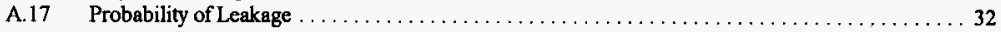

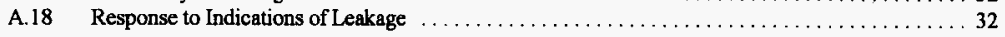

APPENDIX B: PREVIOUS STUDIES AND FINDINGS RELATED TO LDMM $\ldots \ldots \ldots \ldots \ldots$

Table B-1: Summary of Scope for LDMM Supporting Documentation $\ldots \ldots \ldots \ldots \ldots \ldots$

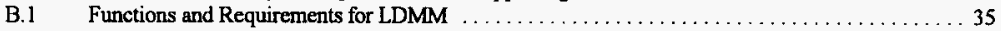

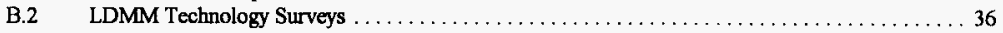

B.3 Technology Issues Related to SST LDMM $\ldots \ldots \ldots \ldots \ldots \ldots \ldots \ldots \ldots \ldots \ldots \ldots \ldots \ldots$

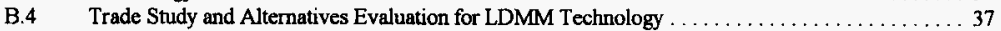

B.5 Operations Response to Leakage During Sluicing $\ldots \ldots \ldots \ldots \ldots \ldots \ldots \ldots \ldots \ldots \ldots \ldots$

B.6 LDMM Technology Field Testing and Demonstrations at Hanford $\ldots \ldots \ldots \ldots \ldots \ldots \ldots \ldots$

APPENDIX C: LDMM CRITERLA FOR DETERMINING ALLOWABLE LEAKAGE $\ldots \ldots \ldots \ldots \ldots \ldots \ldots$ 


\subsection{EXECUTIVE SUMMARY}

Past-practice sluicing has been selected as the method that will be used to remove saltcake and sludge waste from Hanford Site single-shell tanks (SSTs). Sluicing involves the addition of liquid to the SSTs and, therefore, poses the risk that leakage of waste may be initiated, or increased. Since sluicing has been selected, and additional SST leakage is a possibility, attention now focuses on determining "tolerable" leakage volume limits within which retrieval operations can work while still maintaining some degree of control on leakage. The potential impacts due to such leakage (if it should occur) are many and varied. This document proposes a strategy to address these impacts - and to move forward with sluicing while working within predetermined leakage parameters, using currently available/existing operational methods and leak surveillance tools. Criteria have been proposed to capture the relevant issues pertaining to leakage detection, monitoring, and mitigation (LDMM), and allow DOE-RL, the Contractor, Ecology, and Hanford Stakeholders to reach concensus on allowable leakage volumes (ALVs). Technical studies and findings that support the proposed strategy, and ALV criteria, are summarized and referenced. This document specifically addresses LDMM for SSTs at Hanford, Washington.

The M-45 series of Tri-Party Agreement (TPA) milestones address leakage from single-shell tanks, during waste retrieval. The TPA requires the retrieval of waste from the initial single shell tank farm, or the "equivalent" number of tanks, to start by December 31, 2003. The TPA milestone M-45-08-T02 specifies that, "... criteria for determining allowable leakage volumes, and acceptable leakage monitoring, detection, and mitigation measures necessary to permit sluicing operations.", be approved by the Washington State Department of Ecology (Ecology). To meet this milestone, DOE and its contractors will, (1) develop the background and basis for allowable leakage volume criteria, (2) propose appropriate measures to address LDMM, and (3) establish agreement with Ecology regarding the issues and recommendations. This document presents a summary of contractor findings and activities that satisfy goals 1 and 2 . Achievement of goal 3, by DOE, and approval by Ecology, will close TPA milestone M-45-08-T02. This document is prepared for DOE-RL, to support and assist them in dialog and concurrence with Ecology and Hanford stakeholders and is, therefore, subject to revision in order to best accommodate that interaction process.

A strategy is presented that will lead to the assignment of allowable leakage volumes for SSTs targeted for retrieval using sluicing. The strategy is based upon technical studies, field testing of candidate LDMM technologies, and the evaluation of candidate technologies against established LDMM Functions and Requirements (F\&Rs) for the Tank Waste Remediation System (TWRS). In summary, the strategy involves the following major steps:

- Identify the target tank farm and SST slated for waste retrieval

- Establish candidate allowable leakage volume (ALV) criteria

- Address applicable criteria (i.e., issue resolution, decision-making)

- Establish a "first pass" value for allowable leakage from the target tank 
- Establish retrieval operations concurrence and verification of the proposed allowable leakage volume

- Obtain Ecology/DOE/Stakeholder/Contractor concurrence and approval of allowable leakage volume

- Initiate retrieval action (i.e., sluicing) within bounds of the established allowable leakage volume

Even though the individual steps of the strategy are brief and few in number, the process of working through the strategy presents sufficient flexibility to allow either detailed or summary actions to occur at each stage. Following the proposed strategy will produce opportunities for resolution of issues, and produce a documented path toward concensus and approval of final ALVs.

The ALV criteria incorporate, and prioritize, the major issues related to the assignment of a leakage range within which SST waste retrieval/sluicing can proceed. Verification and finalization of applicable criteria (i.e., for the tank under consideration) is part of the recommended LDMM strategy. An allowable leakage volume can be assigned to every SST by achieving resolution on a set of applicable criteria. An initial listing of candidate criteria for determining allowable leakage has been prepared (Table $1 \mathrm{a}$ and Section 5.0). Each criterion requires closure, or resolution, by making decisions regarding associated issues. Such decisions will be required on regulatory, management and policy, and technical and operations issues. The resolution of these issues may vary from tank to tank as the waste retrieval effort proceeds due to the need to reevaluate previous decisions based upon the results of ongoing and prior retrieval campaigns. When all criteria have been addressed an allowable leakage volume, or range, will have been determined for the tank and tank farm under study. Resolution of the applicable LDMM-related criteria will also establish a safety basis for the final ALV assignment.

The criteria for determining allowable leakage address issues and decisions regarding potential leakage events at three major levels of magnitude. The three major levels, or tiers, are as follows:

Tier-1 SOL CAPACITY VALUE - A bounding value for the capacity of soil, beneath a target tank or tank farm, to retain water and/or leaked waste.

The soil capacity value represents the maximum leakage volume that the soil can "tolerate" before rendering impractical the remediation of unacceptable contamination. If not remediated within the next 30 years (as part of SST closure operations), leakage of this magnitude would have a high potential to eventually reach the aquifer underlying the 200 areas plateau. Long term public health and environmental impacts have not been evalutated for a leakage event of this magnitude.

Tier-2 MAXIMUM POTENTIAL LEAKAGE - The maximum leakage event that could occur from a target tank due to a retrieval action, such as sluicing.

The difference between Tier- 1 and Tier- 2 leakage values provides a measure of the effectiveness of the soil beneath the tank to provide interim protection of the 
groundwater... if a Tier-2 leakage volume were to be released. The risks associated with this maximum volume of leakage should be judged "acceptable" before proceeding with sluicing (i.e., due to the lack of significant and absolute control over leakage once it occurs and the inaccuracy with which leakage can be detected).

Tier-3 MINIMUM PRACTICABLE ACHIEVABLE LEAKAGE (MPAL) - Leakage limits will be imposed [on operations] as a means of optimizing the potential for cost-effective and compliant closure of the tank farms following sluicing.

These are leakage limits, lower than the Tier-2 level, that will serve as goals and constraints within which retrieval action can proceed. MPAL levels will be determined as a final product of the allowable leakage criteria resolution process and will appear as a subset to the ALV operations envelope, within which sluicing will be carried out. These values are expected to vary from tank to tank. Actions that can be employed to attain MPAL include: sequencing tanks based on leakage risks, employing pre-approved operational leakage response actions, enhancing design of sluicing equipment, increasing availability of replacement sluicing equipment, and maximizing the use of currently available LDMM technologies and methods.

Criteria resolution is not a Contractor-only action, there are key decision-making functions (i.e., Ecology, DOE, Contractor) involved with each criterion. Several of the criteria require regulatory approval or concurrence, and others require DOE and Contractor agreement. Retrieval operations, using existing tools and methods for LDMM, must be capable of functioning within the assigned envelope for allowable leakage. The final criteria and resulting ALV, therefore, will require verification and approval by the retrieval operations function. Table la shows the relationship of allowable leakage criteria, the three leakage tier levels, and the major decision-making levels. Appendix C provides the complete reference document (FW-1996c) discussing each of the criterion in detail. 
Proposed Strategy for LDMM During Hanford SST Waste Retrieval (WHC-SD-WM-ES-378, Rev 0)

Table 1a: Allowable Leakage Criteria Related to Leakage Tier Level and Decision Levels

\begin{tabular}{|c|c|c|c|c|c|c|c|}
\hline \multirow[t]{2}{*}{ No. } & \multirow[t]{2}{*}{ Allowable Leakage Criteria } & \multicolumn{3}{|c|}{$\begin{array}{c}\text { Tier } \\
\text { Level }\end{array}$} & \multicolumn{3}{|c|}{ Decision Level } \\
\hline & & 1 & 2 & 3 & Regulatory & Mgt/Policy & Tech/Ops \\
\hline 1 & Controlling Risk Scenario & & & $\mathrm{x}$ & $\mathrm{X}$ & & \\
\hline 2 & Risk Models and Data & & & $\mathbf{x}$ & $\mathrm{x}$ & & $\mathrm{X}$ \\
\hline 3 & Point of Compliance & & & $\mathrm{x}$ & $\mathrm{x}$ & & \\
\hline 4 & Period of Compliance & & & $\mathrm{x}$ & $\mathrm{x}$ & & \\
\hline 5 & Constituents of Concern & & & $\mathrm{x}$ & $\mathrm{x}$ & & $x$ \\
\hline 6 & Vadose Zone Flux Distribution & & & $\mathrm{x}$ & & & $\mathrm{X}$ \\
\hline 7 & Allowable Risk & & & $\mathrm{x}$ & $\mathrm{X}$ & & \\
\hline 8 & Tank Sources of Risk & & & $\mathrm{x}$ & & & $\mathrm{x}$ \\
\hline 9 & Leakage Concentrations & & & $\mathrm{x}$ & & & $\mathrm{x}$ \\
\hline 10 & Acceptable Closure Options & $\mathrm{X}$ & & $\mathrm{X}$ & $\mathrm{x}$ & $x$ & \\
\hline 11 & Leakage Volumes & & & $\mathrm{X}$ & & & $\mathrm{x}$ \\
\hline 12 & Aligned Waste Sources & & & $\mathrm{x}$ & $\mathrm{x}$ & & \\
\hline 13 & Risk Aportionment & & & $\mathrm{x}$ & $\mathrm{x}$ & $\mathrm{X}$ & $\mathrm{x}$ \\
\hline 14 & Leakage DetectionTechnology & & $\mathrm{x}$ & $\mathrm{x}$ & & $\mathrm{x}$ & \\
\hline 15 & Leakage Mitigation Technology & $\mathrm{x}$ & $\mathrm{x}$ & $\mathrm{x}$ & & $\mathrm{x}$ & \\
\hline 16 & Individual Tank Characteristics & & $\mathrm{x}$ & $\mathbf{x}$ & & & $\mathrm{x}$ \\
\hline 17 & Exceedance of Allowable Leakage Values & $\mathrm{x}$ & & $\mathrm{x}$ & & $\mathrm{X}$ & \\
\hline 18 & Exceedance of Leakage Ceilings & $\mathrm{x}$ & & $\mathrm{x}$ & $\mathrm{x}$ & & \\
\hline 19 & Absolute Limit on Allowable Leakage & $\mathrm{x}$ & & & $\mathrm{x}$ & $\mathrm{x}$ & $\mathrm{x}$ \\
\hline
\end{tabular}

The LDMM strategy development and Hanford Site closure strategy development are closely coupled, due to the potential impacts of additional leakage on soil contamination. Addressing the criteria for allowable leakage will, therefore, require resolution of issues and decisions pertaining to closure. The following LDMM issues, specifically related to the Hanford SST Closure Work Plan, are included in the allowable leakage criteria: 
- Long term contaminant transport to the environment

- Short term risk to the public and environment during closure

- Long term risk to the public and environment following closure

- Accident and health risk to workers during closure

- Characterization of residual tank waste and contaminated soil

- Leak plume modeling to support NEPA and WAC requirements

Currently available operating methods and LDMM tools are capable of supporting SST sluicing. The following measures will be employed to provide LDMM support during retrieval/sluicing operations in "compliance" with allowable leakage criteria:

- Employ current, in-tank, liquid/waste level measurement devices and methods for leak detection during sluicing.

- Employ current leak plume monitoring devices, and flow modeling data to assess leakage prior to, and after, sluicing (as data contribution to ALV determination).

- Employ available operational, procedural, and administrative methods, and retrieval equipment design and availability, to mitigate leakage prior to and during sluicing retrieval. Engineered systems, beneath tanks, are not available for deployment for leak mitigation.

- Continue to evaluate candidate LDMM technologies, and enhanced existing tools/capabilities, and implement to support the ongoing retrieval action whenever possible and appropriate.

Supporting studies have determined the following concerning the application of leak detection during sluicing operations (Additional details are provided in Appendix B):

- Currently, externally applied technology is incapable of detecting a leak of waste, 1) within the required time frame of sluicing operations, and 2) under existing tank farm conditions (PNL-1994, PNL-1995, FW-1996).

- A leakage indication (i.e., leak detection tool) is of no value for mitigation unless it can provide information within the time frame of waste retrieval/sluicing operations (FW-1996, ARES-1996).

- Deployment of LDMM measures may prove to be more challenging than obtaining a technology that functions as needed. (PNL-1995, FW-1996) 
- A "perfect", available, deployable, etc., leak detection tool is of no value if there is no operational response to the data and information that such a tool would provide (FW-1996, ARES-1996). 


\subsection{OBJECTIVES}

The objective of this document is to propose a strategy for addressing applicable LDMM-related criteria in order to determine an allowable leakage volume for SSTs targeted for waste retrieval using sluicing. A strategy is required to work through the individual ALV criterion (and related issues) in a prioritized, orderly, and efficient manner. All components of the strategy are based upon LDMM-related issues, functions and requirements, and technology alternatives.

An initial listing of the major ALV criterion has been prepared. Resolution of the criteria will lead to determination, on a case-by-case basis, of allowable leakage volumes for individual SSTs and tank farms. The criteria listing that is proposed was prepared with consideration of current issues and concerns, however, the criterion may require revision to accommodate DOE-RL, Ecology, stakeholder, and contractor needs. Application of final allowable leakage volumes, together with the use of current LDMM measures, will permit sluicing of Hanford SSTs.

The scope of this document does not include resolution and decision-making regarding any individual criterion presented. Information regarding the LDMM measures that have been identified, and that are capable of supporting SST waste sluicing, have been incorporated into the criteria statements. Also, this document does not discuss individual SSTs; whether they should be sluiced, when they should be sluiced, or what ALVs should be applied. These items will be the product of the proposed strategy and criterion resolution process.

This is a summary document, with regard to the technical reference material and findings that are cited. The reader is introduced to the content and results of the technical basis through table data and appendix summary. However, the supporting documents are not fully discussed and the reader must review that material in order to gain a full understanding of the technical basis.

TPA milestone M-45-08-T02 (due in April 1997) requires the establishment of criteria to determine (1) allowable leakage volumes and (2) acceptable LDMM measures to permit sluicing operations. This document is prepared by the Contractor, for DOE-RL, to support and assist them in dialog and concurrence with Ecology and Hanford stakeholders regarding allowable leakage and measures for LDMM during sluicing. In summary, this document accomplishes the following tasks that support fulfillment of TPA milestone M-45-08-T02:

- Describes a strategy to determine ALVs for Hanford SSTs

- Proposes candidate criteria for determining ALVs

- Identifies leak detection, monitoring, and mitigation (LDMM) measures that will permit waste retrieval from Hanford single-shell tanks (SSTs) by sluicing

- Summarizes the technical basis documents and activities that support the proposed LDMM strategy and ALV criteria 


\subsection{BACKGROUND}

Regulatory, programmatic, and technical drivers for the preparation of a strategy to address LDMM include the following:

- TPA milestones that state the need for a responsible and viable approach to LDMM during sluicing.

- The Initial Single Shell Tank Retrieval System (ISSTRS) project, that includes a design phase that incorporates an operational approach and technologies to address LDMM during waste retrieval by past-practice sluicing.

- Stakeholder values regarding Hanford site closure, that include the challenge to ensure that any leakage, if it should occur, should be kept to the lowest levels possible (DOE-1993).

- Technical documentation, studies, and LDMM field activities at Hanford

\subsection{Tri-Party Agreement Milestones}

The M-45 series of TPA milestones (Table 3a) address tank leakage, and more specifically, leakage from SSTs, during waste retrieval using past-practice sluicing. The TPA requires the retrieval of waste from the initial single shell tank farm, or the "equivalent" number of tanks, to start by December 31.2003. LDMM to support this activity must be fully addressed by that date, including design and demonstration (M-45-08B).

TPA milestone M-45-08-T02, due in April 1997, requires the establishment of criteria to determine (1) allowable leakage volumes and (2) acceptable LDMM measures to permit sluicing operations. Ecology has final authority for determining acceptable criteria for the April, 1997 milestone. To effect development of the criteria and basis, contractor/WHC, and DOE will provide, 1) an explanation of the issues, 2) a proposed approach, and 3) support to Ecology in their presentation of allowable leakage criteria and LDMM measures to the public. 
Table 3a: TPA Milestones Specifically Related to LDMM

\begin{tabular}{|c|c|c|}
\hline Milestone No. & Milestone Description & Due Date \\
\hline$M-45-08$ & $\begin{array}{l}\text { Establish full scale capability for mitigation of waste tank leakage } \\
\text { during retrieval sluicing operations. }\end{array}$ & $6 / 30 / 2003$ \\
\hline M-45-08-T01 & $\begin{array}{l}\text { Provide preliminary assessment report for projected SST leakage. } \\
\text { Such assessment to project executed environmental contamination } \\
\text { and groundwater health risk using existing waste data. }\end{array}$ & $10 / 31 / 1995$ \\
\hline $\mathrm{M}-45-08-\mathrm{T} 02$ & $\begin{array}{l}\text { Establish the criteria, through stakeholder participation and ecology } \\
\text { approval, for: (1) determining allowable leakage volumes, and (2) } \\
\text { acceptable leak monitoring/detection and mitigation measures } \\
\text { necessary to permit sluicing operations. } \\
\text { Consistent with authorities granted by EPA and the state under its } \\
\text { delegated hazardous waste management program, ecology will have } \\
\text { final authority in determining acceptable criteria for this target } \\
\text { activity. }\end{array}$ & $4 / 30 / 1997$ \\
\hline M-45-08A & $\begin{array}{l}\text { Complete systems design and operating strategy for tank leak } \\
\text { monitoring and mitigation for systems to be used in conjunction with } \\
\text { initial retrieval systems for SSTs. }\end{array}$ & $12 / 31 / 2000$ \\
\hline M-45-08B & $\begin{array}{l}\text { Complete demonstration and installation of leak monitoring and } \\
\text { mitigation systems for initial SST retrieval. }\end{array}$ & $6 / 30 / 2003$ \\
\hline $\mathrm{M}-45-09 \mathrm{~A}$ through $\mathrm{H}$ & $\begin{array}{l}\text { Submit annual progress reports on the development of waste tank } \\
\text { leak monitoring/detection and mitigation activities in support of M- } \\
45-08 \text {. } \\
\text { Reports will provide a description of work accomplished under M- } \\
45-08 \text {, technologies, applications, cost, schedule, and technical data. } \\
\text { Reports will also evaluate demonstrations performed by DOE and } \\
\text { private industry for applicability to SST retrieval and provide } \\
\text { recommendations for further testing for use in retrieval operations. }\end{array}$ & $\begin{array}{l}9 / 30 / 1996 \text { through } \\
9 / 30 / 2003\end{array}$ \\
\hline
\end{tabular}

\subsection{Initial Single Shell Tank Retrieval System}

The Initial Single Shell Tank Retrieval System (ISSTRS) project is an activity within the Hanford Tank Waste Remediation System (TWRS) program that will demonstrate production-scale retrieval of [salt cake] waste, utilizing past practice sluicing, from selected SST's (WHC-1996a and WHC-1996b). ISSTRS will provide the required systems, equipment, permits, approvals, procedures and trained operators needed to retrieve and transfer waste from the first (initial) SST farm to a double shell tank (DST). The amount of waste retrieved will be limited to that which is practical using past practice sluicing. ISSTRS will be the first waste retrieval effort to implement this strategy for LDMM. 


\subsection{Environmental and Closure Considerations}

Hanford Site closure strategy development and LDMM strategy development are closely coupled. LDMM and closure are linked by the impact(s) of additional leakage on soil contamination. Addressing the criteria for allowable leakage will, therefore, include consideration of issues related to closure. Such issues include the following:

- $\quad$ Remediation of contaminated soil within the tank farm operable unit (e.g., should this be carried out as part of the closure process?)

- Assessment of long term and short term risk to the public, workers, and the environment (e.g., should this beconducted for [all] soil remediation alternatives?)

- Existing soil contamination, plus any additional contamination that might occur during sluicing retrieval operations in leaking tanks (e.g., will this be included as source terms in the analyses?)

- Characterization of the species and concentrations of contaminants in the soil, and the geographical extent of contamination (e.g., should this be required to support modeling efforts?)

The combined risks associated with leaks and other non-retrieval sources will be a factor in defining how the SST farms will be closed. It will be necessary to characterize the degree and extent of soil contamination as input to final decisions on soil remediation. If analysis shows that the existing soil contamination in the tank farms is extensive enough to require excavation or treatment as part of closure, then it could be argued that any additional contamination may be of no consequence, and deployment of LDMM may not be justified. However, the opposite argument may be equally valid, i.e., if existing contamination is already extensive enough that soil remediation will be required, then any additional contamination will only make matters worse, and LDMM should be deployed to minimize additional harm. Both sides of this argument could also be taken for a tank farm that is relatively clean, i.e., where not much leakage has occurred, or where the contaminants that have leaked are relatively benign. Contaminant transport modeling and risk assessment supporting tank farm closure will increase understanding of the significance of additional leakage, to overall risk, and the importance of LDMM in reducing that risk.

Preliminary costs associated with exhumation and treatment of tanks and contaminated soil are estimated to be very high (Boomer et al. 1993). Thus, the successful use of LDMM technology could prove to be cost-effective for closing tank farms. If used as a means of detecting and preventing the occurrence of an unacceptable level of soil contamination, LDMM technology may effectively avoid the costly need to exhume tanks and contaminated soil in order to meet closure requirements.

Environmental and closure impacts are not a part of the operations action considerations once sluicing is underway. Deliberations and decisions based on these topics must already have been addressed and "agreed to", based upon potential worst case and anticipated low level (i.e., continue sluicing) leakage events, prior to starting the sluicing effort. Also, prior to sluicing any 
tank or tank farm, the current leakage condition should be assessed to determine whether the risk from potential, future, leakage is enough to outweigh any benefits and risk reduction that would be gained from retrieving the waste. This is a pre-retrieval decision, and one that can only be made before a leak occurs. After a retrieval/sluicing campaign the environmental factor is once again reassessed prior to going on with the next tank or tank farm retrieval effort.

A determination of the likely, overall closure requirements and the "unacceptable" level of soil contamination, is therefore necessary to identify specific functional specifications for an LDMM system that will be deployed to support a given tank, or tank farm.

Modeling will play an integral part in assessing the relative performance and risk of different closure alternatives. Modeling will provide input to the National Environmental Protection Agency (NEPA) process, and support licensing (i.e., through issuance of a closure plan under WACs 173-303 dangerous waste regulations, and classification of residual contamination as incidental waste (i.e., non-high level waste (HLW)) by the Nuclear Regulatory Commission.)

\section{$3.4 \quad$ Supporting Studies and Reports}

The strategy for LDMM and the criteria for determining ALVs have been developed through an ongoing process of technical studies and reporting. A summary listing of studies and tests that form the technical basis for the proposed LDMM strategy is provided in Table $3 \mathrm{~b}$. Specific terminology and definitions, related to LDMM are described in Appendix A.

Table 3b: Summary Liating of LDMM Technical Basis Documents

\begin{tabular}{|l|l|}
\hline DOE-1993 & Hanford Tank Waste Task Force: Final Report \\
\hline WHC-1994 & Technical Bases for Leak Detection Surveillance of Waste Storage Tanks \\
\hline PNL-1994 & $\begin{array}{l}\text { Survey of Existing and Emerging Technologies for External Detection of } \\
\text { Liquid Leaks at the Hanford Site }\end{array}$ \\
\hline PNL-1995 & $\begin{array}{l}\text { Survey and Description of Candidate Technologies to Support SST Waste } \\
\text { Retrieval Leak Detection/Monitoring/Mitigation }\end{array}$ \\
\hline WHC-1995 & Functions and Requirements for Hanford SST LDMM (Revision 0) \\
\hline FW-1995 & Technology Issues Related to SST Waste Retrieval LDMM \\
\hline ARES-1996 & Operational Tank Leak Detection and Minimization During Retrieval \\
\hline FW-1996a & $\begin{array}{l}\text { Trade Study of LDMM Technologies Available for Support of Hanford } \\
\text { SST Waste Retrieval by Sluicing }\end{array}$ \\
\hline FW-1996b & $\begin{array}{l}\text { Functions and Requirements for LDMM to Support Hanford SST Waste } \\
\text { Retrieval (Revision 1) }\end{array}$ \\
\hline FW-1996c & LDMM Criteria for Determining Allowable Leakage \\
\hline
\end{tabular}

These supporting activities and documents present the following findings:

- Decisions regarding allowable leakage should be risk-based 
- $\quad$ Minimum practicable achievable leakage (MPAL) levels can be sustained using current LDMM technologies and operational procedures, while sluicing within an allowable leakage envelope (i.e., maximum actual leakage less than established ALV)

- Currently, in-tank liquid level measurement is the only leakage detection/determination capability that satisfies LDMM F\&Rs

- $\quad$ Candidate LDMM technologies have potential to provide cost benefits and risk reduction, and should be pursued simultaneously with retrieval operations that utilize baseline methods (i.e., in-tank level measurements)

- Current external leakage plume monitoring efforts (i.e., using borehole gamma and neutron logging devices) could provide some pre- and post-retrieval information

- Response times, detection levels, and soil mass coverage of available external leakage monitoring devices are insufficient for go/no-go decisionmaking while sluicing is in progress

- Among all candidate monitoring technologies studied, cone penetrometer technique (CPT)-deployed electrical resistance tomography (ERT) is the leading choice for potentially meeting pre- and post-sluicing leakage concurrence and assessment needs

- There are no barrier technologies which can be engineered and deployed to mitigate leaks beneath Hanford tanks

- The lack of any leakage mitigation devices limits operational response to leakage to either stopping the ongoing activity or continuing

- Go/no-go decisions will include evaluation of leakage rate and volume data vs threshold leakage values, along with consideration for the stage/progress of waste removal.

\subsection{LDMM Field Activities}

Simulated leak tests were conducted at the Hanford 200 East Area 105A Mock Tank Leak Test Site to develop and demonstrate the capabilities of candidate leakage monitoring and detection technologies. These field tests allow evaluation of such techniques as electrical resistance tomography (ERT) prior to demonstration and use in an actual tank farm. Field testing also contributed to the establishment of LDMM F\&Rs and the trade study alternatives evaluation criterion. Field testing of ERT was carried out at Hanford during the period FY-94 through FY96 , and is planned to continue during FY -97 . Table 3c provides a summary of the goais and accomplishments of recent field demonstrations and tests: 
Table 3c: Summary of FY-94 through FY-97 Hanford LDMM Field Activities

\begin{tabular}{|l|l|}
\hline FY-1994 & $\begin{array}{l}\text { Leak test site constructed at the Hanford 200E 105A Mock Tank location. Lawrence Livermore } \\
\text { National Laboratories (LLNL) performed ERT leak detection and monitoring tests using 16 (40ft } \\
\text { deep) vertical electrode arrays (VEAs), each with 8 electrodes. Two simulated leak tests were } \\
\text { performed demonstrating ERT capability to "detect" single-point leaks of 4-8 gallons per minute } \\
\text { down to approximately 200 gallon initial indication volume. Two and three-dimensional } \\
\text { tomographic data were produced. }\end{array}$ \\
\hline FY-1995 & $\begin{array}{l}\text { Two additional leak tests were conducted by LLNL using different (more challenging) leak location } \\
\text { and liquid flow conditions. Improved ERT data collection and calculation techniques were } \\
\text { employed. }\end{array}$ \\
\hline FY-1996 & $\begin{array}{l}\text { Applied Research Associates, LLNL, and WHC joint task to design, fabricate, deploy, and test cone } \\
\text { penetrometer deployed ERT VEAs at Hanford leak test site. Four VEAs installed to i30 feet depth } \\
\text { successfully proving the capability to deploy electrodes by a more feasible, inexpensive, safer method } \\
\text { than conventional [drilling] emplacement techniques. Final testing before actual in-tank farm } \\
\text { deployment is undertaken. }\end{array}$ \\
\hline $\begin{array}{l}\text { FY-1997 } \\
\text { (planned) }\end{array}$ & $\begin{array}{l}\text { CPT-deployment of ERT VEAs in actual Hanford SST tank farm planned. Anticipated challenges } \\
\text { include: logistics of working in the tank farm, cathodic protection (electrical) "noise", collection of } \\
\text { ERT data around a full-scale SST "metal anomaly", rocky soils, achievement of desired depth (70 - } \\
\text { 150 feet). }\end{array}$ \\
\hline
\end{tabular}




\subsection{STRATEGY TO DETERMINE ALLOWABLE LEAKAGE VOLUME}

A strategy is proposed to select and resolve relevant criteria in order to determine an allowable leakage volume for an SST selected for sluicing. Implementing the strategy will involve several stages of interaction between the Contractor, DOE-RL, Ecology, and Hanford Stakeholders in order to reach a concensus and final approval on individual ALV's. Use of the strategy will not only ensure an efficient and orderly movement through relevant criteria and issues, but will also provide a documented basis for the final ALV and a record of assumptions, decisions, and dialog that occured during the process. The major stages of the proposed strategy are as follows:

- Identify the target tank farm and SST slated for waste retrieval

- Establish candidate/applicable allowable leakage volume criteria

- Address applicable criteria (i.e., issue resolution, decision-making)

- Establish a "first pass" value for allowable leakage from the target tank

- Establish retrieval operations concurrence and verification of the proposed allowable leakage volume

- Obtain Ecology/DOE/Stakeholder/Contractor concurrence and approval of allowable leakage volume

- Initiate retrieval action (i.e., sluicing) within bounds of the established allowable leakage volume.

The final goals of the strategy "process" are to (1) ensure that applicable issues have been addressed and criteria met, (2) develop concensus between all parties (i.e., DOE-RL, Ecology, Stakeholders, Contractor) regarding the final ALV decision, (3) provide an ALV to operations that is feasible using current LDMM technology, sluicing equipment design, and operational methods. There are stages within the strategy that involve issue resolution and decisionmaking. There is a complete flexibility available in working through these stages. The strategy provides for a varied degree of deliberation in addressing criteria, and the related issues; from extensive, rigorous, debate to one-meeting signoff. The most important aspects of the strategy are that all issues are addressed, to some degree, and that their is concensus to the decisions and final ALV.

The proposed strategy includes identification and addressing applicable ALV criteria. Establishment of operational leakage parameters will be achieved by risk-based decisionmaking applied to the set of applicable criteria. An initial listing of candidate, allowable leakage criteria has been prepared (Section 5.0). It is recommended that each criterion be addressed in sequence, in order to establish the final ALV. This is due to the fact that some upper level issues and decisions are contained in the earlier criterion. Time and effort in addressing later criterion may well be wasted if key issues and decisions, identified in earlier 
criterion, are not resolved beforehand, and are not available. Resolution of individual criterion could potentially involve the following, minimum steps:

- $\quad$ Preparing and documenting enabling assumptions

- Obtaining and reviewing required data

- Identifying relevant issues and interactions with other criteria

- $\quad$ Addressing all relevant issues to a "concluding point"

- $\quad$ Making decisions, as required

- Developing clear criteria resolution statements

- Closing out the criteria: concensus and signoff 


\subsection{CRITERIA FOR DETERMINING ALLOWABLE LEAKAGE}

Criteria are defined as "standards upon which judgement(s) or decision(s) can be made." The criteria to determine allowable leakage volumes were prepared as representative of, and encompassing, the major issues and decisions related to potential SST waste leakage. The criteria address the following major topics:

- $\quad$ Allowable leakage from an SST during sluicing operations should be based on relevant regulatory (e.g., National Environmental Protection Agency (40 CFR 1500-1508, 10 CFR 1021)), policy, and technical/operational criteria .

- Criteria for determining ALVs should be supported by accepted and/or approved enabling assumptions and data.

- Resolution of issues will require a combination of DOE and Ecology concurrence/approval, policy decisions, guidance, and improved data.

LDMM issues addressed by these criteria include the following:

- $\quad$ SST closure

- $\quad$ SST's at risk of leaking

- Environmental and health impacts of leakage

- Allowable range of leakage to permit sluicing operations

- Available and deployable LDMM technologies

- Operational response to leaks

- Candidate LDMM technologies vs baseline

- Proceeding with baseline while considering new technologies

Table 5a lists the (proposed) major criterion that must be met in order to determine ALVs for preand post-retrieval decision making, and upper operating ranges. Appendix $\mathrm{C}$ provides a copy of the complete document identifying LDMM allowable leakage volume criteria. 


\begin{tabular}{|c|c|}
\hline Criterion No. 1 & Identify the controlling risk scenario to determine how much leakage is harmful \\
\hline Criterion No. 2 & $\begin{array}{l}\text { Identify the mathematical models, boundary conditions, and input data to be used to simulate the } \\
\text { controlling risk scenario }\end{array}$ \\
\hline Criterion No. 3 & Establish the point of compliance [for modeling/assessment] following closure of a tank farm \\
\hline Criterion No. 4 & Establish the period of time over which compliance must be assured \\
\hline Criterion No. 5 & $\begin{array}{l}\text { Determine the components of SST waste that should be considered constituents of concern } \\
\text { (COC) }\end{array}$ \\
\hline Criterion No. 6 & $\begin{array}{l}\text { Establish the pattern and area for tank farm groupings and tanks that should be used to calculate } \\
\text { COC flux from postulated leakage }\end{array}$ \\
\hline Criterion No. 7 & Establish allowable risk to the Maximally Exposed Individual (MEI) onsite residential farmer \\
\hline Criterion No. 8 & $\begin{array}{l}\text { Establish whether other/all [past] risk impacts should be considered in addition to the risk } \\
\text { impacts of residual tank waste and new leakage }\end{array}$ \\
\hline Criterion No. 9 & $\begin{array}{l}\text { Determine the methods that should be used to estimate the concentrations of COCs in leakage } \\
\text { and the residual tank waste }\end{array}$ \\
\hline Criterion No. 10 & Identify and establish the acceptability of closure options \\
\hline Criterion No. 11 & Establish the [best] method for quantifying the volumes of past and future leakage \\
\hline Criterion No. 12 & $\begin{array}{l}\text { Establish whether the impacts of upgradient and downgradient groundwater contamination } \\
\text { should be included in risk estimates }\end{array}$ \\
\hline Criterion No. 13 & $\begin{array}{l}\text { Determine the apportionment of allowable cumulative risk among the contributing sources when } \\
\text { two or more plumes overlap }\end{array}$ \\
\hline Criterion No. 14 & $\begin{array}{l}\text { Determine the impact of leak detection and response technology on reducing the amount of new } \\
\text { leakage that may occur during sluicing }\end{array}$ \\
\hline Criterion No. 15 & $\begin{array}{l}\text { Determine which leakage mitigation technologies are viable and how much impact they will } \\
\text { have on reducing leakage }\end{array}$ \\
\hline Criterion No. 16 & $\begin{array}{l}\text { Consider the design and physical characteristics (condition) of individual tanks when defining } \\
\text { allowable leakage }\end{array}$ \\
\hline Criterion No. 17 & Determine the consequences of exceeding an allowable leakage value \\
\hline Criterion No. 18 & $\begin{array}{l}\text { Establish whether sluicing should be allowed when their is likelihood of exceeding a leakage } \\
\text { ceiling }\end{array}$ \\
\hline Criterion No. 19 & $\begin{array}{l}\text { Establish whether an absolute limit should be imposed on the amount of leakage allowable to } \\
\text { ensure protection of the groundwater }\end{array}$ \\
\hline
\end{tabular}

\subsection{Major Leakage Boundaries Addressed by ALV Criteria}

Three major "leakage boundaries", or tiers, are recommended to establish allowable leakage values: (1) [site-specific] soil capacity value, (2) maximum potential leakage [due to retrieval by sluicing], and (3) minimum practicable achievable leakage - leakage constraints that will be 
imposed upon operations during actual retrieval/sluicing activities. This three-tiered approach to defining leakage boundaries is discussed in the following sections.

\subsubsection{Soil Capacity Value}

At Tier-1 a combination of historical and theoretical data will be evaluated and compared with vadose zone modeling data to produce a bounding value for the leakage retention capacity of soil beneath a target tank and/or tank farm. This value will represent the greatest volume of liquid waste (maximum tolerable leakage) that could be expected to penetrate into the surrounding soil to a depth that would not preclude remediation. The modeling applied for this decision would include consideration of existing leakage plumes, and local soil and hydrology characteristics. This volume provides the first level of maximum tolerable leakage volume. Leakage greater than this magnitude, if not remediated, would have the potential to impact the groundwater within several decades and would substantially contaminate the soil in and around the target tank.

\subsubsection{Maximum Potential Leakage}

Maximum potential leakage is the volume of leakage that could result from a leak that included all the liquid/waste that is already present in the target tank, together with the liquid that is added due to the sluicing process. A comparison between the volume of a maximum potential leakage that could occur from a target tank due to a retrieval action such as sluicing (Tier-2), and the Tier- 1 soil capacity value should be made. The Tier- 2 maximum potential leakage would occur if the leakage detection and response system failed to detect and mitigate catastrophic leakage that occurred near the beginning of retrieval operations (i.e., the time at which the greatest potential volume of liquid is still "available" to be leaked). The difference between Tier- 1 and Tier- 2 leakage values provides a measure of the effectiveness of the soil beneath the tank to ensure interim protection of the groundwater, if the maximum leakage were to occur. Even though the potential for the occurrence of maximum volume (Tier-2) leakage is very small, there is no guarantee against it. This is due to the lack of significant and absolute control over leakage once it occurs, and the inaccuracy with which leakage can be detected using currently available technology. Therefore, the risks associated with this maximum volume of leakage should be judged as "acceptable" before proceeding with sluicing.

\subsubsection{Minimum Practicable Achievable Leakage}

Tier-1 analysis will establish the maximum volumes of leakage allowable to ensure interim protection of the groundwater. In most cases the maximum potential leakage determined in the Tier- 2 analyses will be less than Tier- 1 levels. Lower levels of allowable leakage (Tier-3) will be imposed to create an even greater degree of protection. The Tier-3 levels serve as constraints within which retrieval actions/sluicing can proceed. Actions that will help attain these limits, and the goal of minimum practicable achievable leakage (MPAL) could include the following: 
- Sequencing tanks for retrieval based on potential leakage risks

- $\quad$ Preparing pre-approved operational response actions for various volumes and speed of leaks [that are within the ALV envelope]

- Enhanced design, and increased availabiity, of sluicing equipment

- Modifying current operations procedures and decision-making plans

- Making maximum use of currently available technologies and methods.

The concept of MPAL is similar to that of ALARA (As Low As Reasonably Achievable), as applied to reduction of exposure to radioactive materials. Even though an ALV is established, which represents a maximum value for leakage during sluicing, the goal of MPAL is to complete the retrieval task with the least leakage possible within the constraints of budget (i.e., cost-benefit) and technical/operational capability. 


\subsection{ACCEPTABLE MEASURES FOR LDMM}

The following measures are available and will be applied to address leak detection, monitoring, and mitigation during SST waste retrieval using past-practice sluicing:

\subsection{Leak Detection Measures}

- Current/baseline operational methods and in-tank liquid level measurement devices (e.g., material balance, flow measurement, visual level indication, etc.) will be used to determine if leaks are occurring during sluicing (ARES-1996).

\subsection{Leakage Plume Monitoring Measures}

- Due to the long time frame (e.g., weeks, months, years) within which leakage plume "movement" occurs, external leakage monitoring tools do not contribute information that is useful during ongoing sluicing/retrieval actions. Leak monitoring tools (i.e., those methods and technologies that do not meet the criteria of leak detection tools) will be applied as part of pre- and post-retrieval activities

- Monitoring tools, and data, will be used to support risk-based decision making - an essential part of the LDMM strategy. Monitoring tools will contribute data regarding leakage concurrence and verification (after a sluicing campaign) and assessment (prior to, AND after, a sluicing campaign).

- Currently available, external "monitoring" tools (e.g., borehole logging via neutron and gamma probes) will continue to be used until more efficient technology can be developed and applied.

\subsection{Leakage Mitigation Measures}

- No new or candidate leakage mitigation devices/technologies have been identified as currently available and/or deployable to support initial SST waste retrieval/sluicing activities

- Leakage mitigation will be achieved through the application of operational methods and procedures, and through the design and availability of equipment to minimize retrieval down-time

- If leakage occurs during waste retrieval, pre-determined, risk-reducing decision logic will be employed to enhance the achievement of leakage minimization and mitigation (i.e., MPAL goal). 


\subsection{Incorporation of Future/Candidate LDMM Technologies into Retrieval Activities}

- New and candidate LDMM tools will be pursued simultaneously while performing SST waste retrieval activities

- New and "enhanced old" technologies will be evaluated and incorporated, as they become available, during the retrieval effort

- New LDMM tools will be incorporated into retrieval operations through a managed program of development, demonstration, evaluation, and eventual operational deployment

- Currently available (i.e., baseline) leakage monitoring tools should continue to be maintained and used, and will play an important role in preparing risk-based decisions for retrieval and closure.

Even though there are few candidate LDMM technologies currently on the horizon for development and demonstration (PNL-1995, FW-1996), this strategy emphasizes the need for a continuing check of these resources for possible future use. As candidate technologies mature and run the gauntlet of development, demonstration, testing, evaluation, deployment, and reliability testing, they will be moved closer and closer to the role of contributing, LDMM tools that can play a part in retrieval operations. LDMM functions and requirements have been clearly defined, and the operational response and constraint elements have been identified. The early-on screening of candidate technologies can now be performed through inexpensive "interviews" and reviews of capabilities for technology providers. 


\section{ACRONYMS}

ARAR applicable or relevant and appropriate requirements

ALV

allowable leakage volume

CAT

currently available technology

CPT

cone penetrometer technique

DOE

U.S. Department of Energy

ERT

electrical resistance tomography

FIC

Food Instrument Corporation

HVAC

heating, ventilation, and air conditioning

ISSTRS

TWRS Initial Single-Shell Tank Retrieval System

LDMM

leak detection, monitoring, and mitigation

LTV

leakage threshold value

MPAL

NEPA

PLV

RCRA

SST

TDR

minimum practicable achievable leakage

National Environmental Protection Agency

potential leakage value

Resource Conservation and Recovery Act of 1976

single-shell tank

TPA

time domain reflectometry

Tri-Party Agreement, Hanford Federal Facility Agreement and Consent Order

TWRS Tank Waste Remediation System 


\section{REFERENCES}

ARES-1996 ARES 951126-001, ARES Corporation, "Operational Tank Leak Detection and Minimization During Retrieval’, February 1996 (WHC-SD-WM-ES-377)

DOE-1993 "Hanford Tank Waste Task Force: Final Report", prepared jointly by Ecology, US-DOE, and the EPA, September 1993

FW-1995 FWRD-WHC/4344-L-95-085, Foster Wheeler Environmental Corp. document, "Technology Issues Related to Single-Shell Tank Waste Retrieval Leak Detection, Monitoring, and Mitigation: Final Report", July 1995

FW-1996a FWRD-WHC/4344-L-96-058, Foster Wheeler Environmental Corp. Document, "Functions and Requirements for Leak Detection, Monitoring, and Mitigation to Support Hanford Single-Shell Tank Waste Retrieval', May 1996

FW-1996b FWRD-WHC/4344-L-96-038, Foster Wheeler Environmental Corp. Document, "Trade Study of LDMM Technologies Available for Support of Hanford SST Waste Retrieval by Sluicing", May 1996 (WHC-SD-WM-ES-379)

FW-1996c FWRD-WHC/4344-L-96-074, Foster Wheeler Environmental Corp. Document, "LDMM Criteria for Determining Allowable Leakage", May 1996 (WHC-SDWM-ES-392)

PNL-1994 PNL-10176, PNL Document, “A Survey of Existing and Emerging Technologies for External Detection of Liquid Leaks at the Hanford Site", October 1994

PNL-1995 PNL-10755, PNL Document, "A Survey and Description of Candidate Technologies to Support Single Shell Tank Waste Retrieval Leak DetectionMonitoring/Mitigation", September 1995

TPA-1989 Hanford Federal Facility Agreement and Consent Order, May 1989 (Current rev.)

WHC-1994 WHC-SD-WM-TI-573, WHC document, "Technical Bases for Leak Detection Surveillance of Waste Storage Tanks”, 1994

WHC-1995 WHC-SD-WM-FRD-021, WHC document, "Functions and Requirements for Hanford Single-Shell Tank Leakage, Detection, and Monitoring", April 1995

WHC-1996a ISSTRS Approach Plan for ISSTRS Definition Effort, WHC Document, WHCSD-WM-AP-039, dated 8/30/95

WHC-1996b Preliminary Design Requirements Document for ISSTRS, WHC document, WHCSD-WM-xxx-DRD-001, Rev 0, dated 6/96 


\section{APPENDIX A: TERMINOLOGY AND DEFINITIONS RELATED TO LDMM}

Several terms and definitions are used frequently in documentation and communications regarding LDMM. As the process of determining criteria, addressing regulatory requirements, and understanding operational constraints proceeds, the need for consistency in terminology and definitions becomes more and more important. This appendix is provided to introduce the majority of terms that are used, and to establish a consistent interpretation of their meaning.

\section{A.1 Allowable Leakage}

Allowable leakage is a major element of the TPA M45-08-T02 activity. A value for "allowable" leakage, from a given tank, is a volume of waste that is considered tolerable when weighed against all the potential risks associated with waste retrieval from that tank, including the following:

- Physical conditions of the tank

- Current leak plume conditions in the target tank farm

- Type of waste

- Geology of the soils in, around, and beneath the target tank/tank farm.

When a tank is selected for sluicing/retrieval action the determination of allowable leak size will include consideration of all these risks. Previous Hanford Site tank leak experience and history, and leak plume/flow modeling, will provide the most important information. During pre-retrieval decision-making, the total available liquid in the target tank, and the anticipated additional liquid that will be added during the retrieval action, will be included in the process to determine Tier- 2 maximum potential leakage volume. This volume will represent the maximum, worst case, leakage volume that could be expected from retrieval action involving the target tank. This volume represents a leakage size that will be considered the allowable leakage volume for that tank. Even though all actions by operations to remain within the Tier 1 allowable leakage guidelines will focus on attaining MPAL, this volume will be retained as the primary, bounding value.

Another definition of allowable leakage can be obtained by evaluating whatever leakage detection method or device is employed. An allowable leak is, initially, any leak that cannot be "seen" by the baseline leak determination, or detection, method. Any volume below the minimum "detection" level of whatever device or method that may be in place, must be considered acceptable. This level represents a blind spot for detection, and a specific leak volume that can conceivably occur unnoticed, especially during the time frame of a typical retrieval campaign (i.e., a few weeks to approximately 120 days). 


\section{A.2 Cumulative Allowable Risk}

The cumulative allowable risk is the maximum acceptable risk to the designated receptor. The primary receptor used in the TWRS EIS was the Maximally Exposed Individual (MEI) which was assumed to be an onsite farmer. The risk is the cumulative contribution from all risk sources including tank leakage (old and new), tank waste residual, and discharges from aligned ponds, cribs, ditches, and burial grounds. The generally accepted upper limits of risks following cleanup of waste sites are an incremental lifetime cancer risk of 10-4 and a hazard index of 1.0.

\section{A.3 Currently Available LDMM Technology}

The only LDMM technologies that can support planned/schedule retrieval actions are those that are currently available. Currently available technology (CAT), as determined through studies of existing and candidate LDMM technologies and the Functions and Requirements for LDMM, are those that are ready for immediate use at the time of retrieval operations. This readiness must include proven field use with a history of reliable, data-producing service. The technology must also be deployable to the point of use (i.e., around the SST or in the tank farm), since in most cases the technology is only useful if it can be deployed in a specific location, or to a required depth, etc.. The Operations Response document (ARES-1996) and the LDMM Technology Trade Study (FW-1996) provide a summary and listing of candidate technologies compared to the base-case, existing and currently used, LDMM methods and devices. For example, the only CATs for use to support retrieval for leak detection are the existing in-tank liquid level measurement methods and, where available (in very few tanks), leak detection pits.

\section{A.4 Leak}

A leak is the point or path at which a loss of a contained material (in this case, a liquid waste) occurs. Leakage is the event wherein a contained material or liquid is in the process of "escaping" from a vessel or structure. In a very strict sense, leakage occurs when even the smallest amount of a material moves to the outside of the containment vessel.

\section{A.5 Leak Detection}

Ideally, for maximum control of a confined material, it is desirable to know the exact time when leakage starts, or initially started, for even the smallest fraction of the total inventory. Pursuit of this information, by whatever means are available, is leak detection. With a highly refined leak detection capability (i.e., low detection level), the opportunity for a favorable mitigating response within a minimum amount of time has the potential to lower risk due to leakage.

During waste retrieval, leakage detection/determination information will contribute to decisionmaking regarding continuing or stopping sluicing. Leak detection capability and information can play an immediate and significant role in achieving the goal of MPAL. Leak detection data that is reliable and provided in a timely fashion (i.e., at intervals that are meaningful and useful to support operations decisions) will be used to advantage. The lower the leak detection level, and the faster the information is obtained, the faster the operational decisions can be made to continue sluicing/retrieval or to stop and pump out all available liquid. 


\section{A.6 Leak Detection Time/Operations Response Envelope}

Leak detection time refers to the amount of time between the moment that a leak actually occurs, and the time that the detecting device, or method, observes that event and relates the information/observation to cognizant instrumentation or workers. The leak detection time, therefore, represents an operational requirement and a functional constraint. A "perfect" leak detector would be the one that provides instantaneous indication that even a minute leak has started, and the detection time for such a device would be "zero". No such device or method currently exists, or is likely to exist, therefore the most valuable next choice is a method or device that comes closest to the zero, or instantaneous goal.

A leak detection device or method must provide information within an operations "response envelope", that is, a time frame during which any possible response will have a positive benefit to mitigating or reducing the volume of the leak. For example, a device that provides "perfect" data about a leakage event, but that requires three months to obtain and report the data, is of no value if the retrieval action being monitored will only last for two weeks. The leak detection announcement that a leak has occurred, must fall within the overall time frame for the retrieval campaign, and typically within far less time, e.g., within the time that the first half of the total waste volume is expected to be retrieved. Data about leakage will become less and less important as the total volume of waste is removed, since the risks of leakage while continuing retrieval will begin to be less than those that would result if the effort were stopped. Therefore, under the challenge of MPAL, detection sensitivity and fast response time is of more concern/use during the early stage of a sluicing campaign.

\section{A.7 Leak Direction}

Leak direction simply refers to information about where the leak plume is headed. Information about the direction of a leakage plume contributes data to assist in the following:

- The process of decision-making regarding the establishment of Tier-2 and Tier-3 leakage projections and operational leakage constraints

- The process of risk-based decision-making about closure

- The impacts of retrieval action to existing tank farm and site contamination conditions.

Unlike information and data about leak rate and volume, that can be acted upon during waste retrieval/sluicing operations, leak direction information is not immediately useful. Leakage direction determination requires longer term monitoring, and can only be developed (using currently available leakage plume monitoring tools) after a retrieval action is completed.

\section{A.8 Leakage Monitoring vs Leakage/Leak Monitors}

Leakage monitoring refers to the activity of maintaining vigilance over the soils surrounding, and beneath, the target tank and/or tank farm (i.e., the tank that is about to be sluiced, or which has previously been sluiced) in an effort to: 
- Assess initial conditions

- Assess any possible leakage that may occur during retrieval/sluicing

- Concur [with leak "detection" indications] that leakage may have occurred during sluicing.

Leak monitors are those devices or methods that can be applied for this purpose, either in-tank, or more typically, exterior to the tank. Monitoring efforts and devices will not be of value during a sluicing campaign to provide input to operational go/no-go decisions. This is because only limited, qualitative information can be provided by monitoring activities, and such data would be provided outside of the time frame for operational response action.

Exterior tank monitoring is a qualitative tool that does not produce specific, detailed data. Currently, existing leakage plumes, and leaks that may be occurring at the present, are being monitored to the greatest extent that current technology allows (primarily using borehole logging techniques). Leakage plume monitoring, even with existing technologies, will continue as both a pre- and post-retrieval evaluation and decision-making tool. Prior to sluicing, a tank/tank farm sub-surface leakage condition will be baselined to establish a comparison against which planned retrieval action/success can be measured. As a post-sluicing tool leakage monitoring will provide general tank perimeter assessment and possible leakage/non-leakage concurrence.

Existing and candidate devices and methods that do not fulfill the established requirements to be classed as leak detectors can generally be considered as leak monitors. A candidate leak detection tool is anticipated to move into a position of standard use by first being deployed as a monitor. As the tool/method is refined, developed, tested, evaluated, and proven to be reliable, then there will be consideration for implementation as a detection device. 


\section{A.9 Leak Mitigation}

Leakage mitigation refers to the systems and/or actions that may be applied to eliminate or minimize the possibility or impact of leakage. Leak mitigation reduces the potential leakage value (PLV).

The potential for leakage is mitigated by controlling the following aspects of the sluicing process:

- $\quad$ Amount of sluicing liquid (reduces liquid available for leaking)

- Direction/placement of the sluicing stream

- Tank liquid level (maintains hydraulic "head" to minimum levels)

- Waste sludge profile (provides protection to the tank liner)

- Minimizing sluicing system down time (reduces time for leakage to occur)

Study WHC-1995 determined that it is not feasible to use current technology, external to tanks, to mitigate leaks. Deployment, verification, and operation of mitigation systems (e.g., barriers, with soil washing) is not achievable with net benefit due to the severe engineering challenge of working beneath Hanford tanks. If deployed, barriers would shift and concentrate the leakage front.

\section{A.10 Leakage Threshold Value}

The leakage threshold value (LTV) represents a volume of leakage [from a tank/SST] that equates to an acceptable risk to human health. LTVs vary from one tank to another and therefore provide relative information about SSTs, and tank farms. LTVs should not be interpreted as "allowable" leakage volumes, and LTVs are not intended to be cited as operating limits for leakage, or as allowable maximums.

LTVs provide an additional data element to aid in the formulation of Tier-3 operations boundaries and constraints. For example, during pre-retrieval decision making and planning for a target tank, if it is determined that the projected leakage value (PLV) during retrieval/sluicing activity, could exceed the LTV, then operational constraints, leakage parameters, controls, and response actions would be imposed, as described in this strategy document.

LTVs provide leakage "sensitivity guidelines" that are part of the information that should be considered during pre-retrieval decision making, and during the formulation of operations response plans [to leakage events]. In this way the LTVs will provide an indication when a projected leakage value (Tier-3 operational leakage boundary) is of particular concem (i.e., is close to, or potentially exceeding the LTV), and requires specific, and perhaps exceptional, operating controls and response actions to ensure actual leakage remains below "allowable" levels.

The LTV (sometimes referred to as Threshold Leakage Values, or TLV) is a risk-based quantity of leakage, calculated for each tank by evaluating the mass, or level, of radioactivity from a tank that may result in risks equal to 1 percent of the cumulative allowable risks. The cumulative allowable risks are assumed to be, (1) an added fatal cancer incidence of $10^{-4}$ to the maximally 
exposed individual (MEI), and (2) a health index value of 1 to the MEI. Risk is determined by transport modeling of potential contaminant(s) leaked from a SST under the following conditions:

- Surface barrier is in place

- Contaminants leach to groundwater

- Contaminants migrate fifty feet down-gradient to a well

- Future resident accesses the well and, over a seventy-year life, is exposed through two liter/day ingestion of groundwater and by eating vegetables irrigated with groundwater.

LTV calculations are made assuming that the tanks are closed without cleaning or removing any contaminated soil (i.e., allowable risks apply to a closed tank farm containing contaminated soil resulting from a leak). The assumption is also made that a surface barrier is established that limits human exposure to the soil, and surface water infiltration of the soil occurs at a rate of $0.05 \mathrm{~cm} / \mathrm{yr}$, during a 30,000 year period.

An initial calculation of LTVs was performed for each SST and documented in the LDMM functions and requirements documents (WHC-1995 and WHC-1996). This effort presented an example of the range of LTV values that were possible using data for that time period, and an example of the relative order of tanks (i.e., lowest LTV vs highest LTV). The LTVs were based on the volume of contaminants of concern (COC) measured in the drainable liquids. The resulting values ranged from $0.05 \mathrm{~L}(0.014$ gallon) to $10,200,000 \mathrm{~L}$ ( $2.7 \mathrm{M}$ gallons). The quality and value of LTVs is highly dependent on the quality, extent, and currency of the supporting data. The LTVs are anticipated to require further periodic updates, as additional, more accurate and complete tank content and characterization data is obtained. Any variations in future calculations of LTVs will primarily be due to changes in the constituents of concern (COCs) and their concentrations within each tank.

Sluicing in some tanks may result in actual leakage that is above LTVs. This is possible since LTVs do not represent the only value that determines a retrieval operations leakage envelope. Pre-retrieval decision-making may result in the establishment of allowable operational leakage amounts that are greater than, or perhaps even less than, current LTVs, based on consideration of other factors including the following:

- Previous leakage amounts

- Residual [in-tank] waste

- Previous leakage and conditions at nearby cribs, ponds, and trenches

- Cleanup requirements during closure

- Land use assumptions. 


\section{A.11 Leak Plume}

A leak plume represents the sum total of all escaping, or escaped, material within the soil mass surrounding a tank. The size of a leak plume is not always directly related to the volume of the original leak and is a function of several variables within the soil mass: porosity, existing moisture content, particle size, hydraulic head for the leaking material, etc.. For example, a leak of several gallons can produce a leak plume that resides in several cubic yards of soil mass.

\section{A.12 Leak Volume, Rate, and Size}

Leak "size" is synonymous with leak volume and refers to the actual amount of material that has escaped from the tank. This data includes existing, pre-retrieval, leak plumes, and the amount of liquid leaked during the course of prior retrieval action. Leak rate, refers to the speed at which a liquid is being released to the environment. Leakage rate and volume data are combined with knowledge about the surrounding soil characteristics to estimate the potential extent of a leak plume, within the surrounding soil.

During waste sluicing, once a leak is underway, there exists only limited control over final leak volume. Operations response is limited to the following:

- Continuing with the retrieval/sluicing action

- Continuing, but with additional cautions, or care

- Stopping all operations and pumping "dry".

Retrieval operations responses to leakage should be based upon the observed leak rate. A "slow" leak rate, that is consistent and within the ALV parameter, will signal that additional sluicing can continue. A "fast" leak rate, that threatens to trend upward at an extreme rate, will probably be indicative of a catastrophic leak, which will indicate immediate stop and pump dry. The goal of such responses is to reduce the extent of the leak and reduce the impacts to the environment (i.e., reduce risk), while still providing the opportunity to retrieve the greatest amount of waste possible. Operational responses will be prepared to limit the final volume leaked, and thus reduce the eventual size of the resulting leak plume.

\section{A.13 LDMM Technology Deployability}

A technology, device, or method for LDMM that cannot be placed into service where it can be used during the waste retrieval activity is not considered to be deployable. The requirement for deployability has become the single most important issue regarding LDMM. Even if a "perfect" device were available, or should become available, fulfilling all other requirements, it must be deployable to be of value. This realization has also brought attention to the need for deployment technology and methods to support LDMM tools. For every LDMM tool, more than likely there will have to be a companion deployment element. No effort to develop a new LDMM tool is complete without including a means for deployment. The method of deployment must be considered simultaneously with tool development to ensure that the method does not interfere 
with the operation of the tool, or that the method does not destroy the tool in the process of emplacement. The tool must be designed to withstand the forces and conditions needed to deploy. Materials must be considered, "communications" with the surface (e.g., wiring) must be included, and even maintainability after emplacement, are all aspects of deployment. The determination of feasibility for a given LDMM technology will be determined in large part by the method, and capability, for deployment.

\section{A.14 LDMM Technology Availability}

Availability refers to whether or not a technology can be obtained, "off-the-shelf", or commercially, for immediate use or deployment. The term "available", when used in this document, means ready for use immediately. Availability cannot be claimed if a device or method is not also deployable. Also, in order to claim availability, an LDMM technology or method much have a record of use at performing the task/technique for which it was designed. This history of use is critical to LDMM to ensure that no false positive, or false negative, indications are produced. A history of use also allows for the development of a statistical basis for detection level and sensitivity. Furthermore, the strategy to use only currently available technology (CAT) for retrieval effort requires that little, if any, additional development, demonstration, evaluation, or implementation effort is required to obtain meaningful, reliable, information as soon as the device/method is installed.

\section{A.15 Minimum Practicable Achievable Leakage}

Minimum practicable achievable leakage is an operational and environmentally responsible goal that is consistent with major Hanford stakeholder values and challenges the retrieval effort to always pursue the most environmentally protective path. The goal of MPAL challenges the retrieval/remediation effort to minimize leakage to the greatest extent possible in a decisionmaking context that includes consideration for operations and final site remediation and closure. During SST waste retrieval/sluicing operations LDMM will be pursued in order to gather data that will assist in decision-making and promote action(s) that will ensure MPAL is achieved. Within the guidelines of the proposed strategy for LDMM, the pursuit and achievement of MPAL is the second major phase of the retrieval effort. Having established a Tier-2, bounding, maximum potential level for leakage from the target tank, and when the decision is made to proceed with retrieval, all efforts will focus on minimizing potential and/or actual leakage to the greatest extent possible (i.e., MPAL) by adhering to Tier-3 operational guidelines and leakage envelope values.

\section{A.16 Projected Leakage Amount}

There is no calculation, method, or technology that can be applied to predict the amount of leakage that may or may not occur from a target tank. Predictions may be attempted based upon assumptions, prior leakage history, or upon previous operational experience. Any attempt to develop a projected leakage amount must consider several variables for each tank, including: the amount of waste to be retrieved, the condition of the tank, and whether or not the tank is a known or assumed leaker, etc.. Such a value would only be useful in pre-retrieval planning and decisionmaking. 


\section{A.17 Probability of Leakage}

Any attempt at estimating the probability of leakage occuring must be based upon assumptions. Similar to projecting the potential volume of leakage, the probability must be based upon the condition of the tank, amount and type of waste, etc. The probability of leakage could possibly be reduced by selecting tanks that are sound, and that are not currently leaking.

\section{A.18 Response to Indications of Leakage}

All operational response actions are focused on attaining, during the sluicing process, the minimum practicable achievable leakage. There are currently only two operationally, and technologically realistic responses possible to a perceived leakage event, 1) go/continue, and 2) stop. There may be various levels of "attention" that could be paid to the go/continue option, as a leak approached the predetermined "stop" point, but within this category the sluicing and retrieval process would still be allowed to continue. Operations will be provided with predetermined, action guidelines that will be followed according to the observed leakage indication (from liquid level measurement). These guidelines would be formulated by considering the accumulated sluice time, the amount of waste retrieved at the time of decision, and leakage threshold action values. A decision-making "gray zone" exists between the time that the leak event is first indicated, and the point at which the perceived leak volume exceeds pre-determined maximum allowable levels. An operational response to continue or stop sluicing must include consideration of the stage of retrieval at the time the decision is needed. For example, decisions made at the time prior to passing the waste retrieval halfway point, may be different than those decisions made after the mid-point. As more and more of the waste is retrieved, the risks associated with stopping sluicing may begin to surpass those incurred by just continuing. These decisions for operational response must be laid out prior to beginning the sluicing campaign, so that they can be referred to in a fast and objective manner, if needed. Increased time for operational response decisions will translate into greater risk due to larger volumes of leaked waste.

An effective LDMM system must not only be capable of detecting a leak before it would cause unacceptable risk, but it must do so in time to initiate and complete actions to stop the leak and prevent creation of unacceptably high risk levels. Signaling that a leak has occurred is of no value if there is no available or planned operational response to leakage information.

For the low-end leakage event, the action range will be the region between the lowest "detectable" change and the upper level value (maximum point at which ops response can favorably respond to the event) for the liquid level measurement technique for the subject tank. Current estimates claim that this value will vary, probably between 4 and $10 \mathrm{k}$ gallons, for all sluicable tanks. As will be discussed in the comment about ops response to a perceived leak, ops actions/responses, the "sensitivity" to perceived leakage, and the upper limit of this action range will move (upward) as the time into the sluicing campaign goes on, and as the waste volume remaining in the tank decreases. This logic says that you "care" less and less, about bigger and faster leaks, as you get further and further into the retrieval effort. When you pass the "point of no return", the risks and penaities for stopping begin to outweigh the consequences of leaking the remaining volume from the tank - so, therefore, continue on as fast as possible and get out of there!

For a catastrophic leakage event (i.e., a leak that exceeds all operational response capability due 
to its speed of onset and rate of leakage) the only option is to cease all operations, remove all liquids remaining, as soon as the condition is realized. The threshold, or action volume/rate for the catastrophic leak will be some predetermined value, significantly above the upper level of the low-leak threshold and possibly "variable", based upon consideration of when the leak occurs, and how much waste has yet to be retrieved. This logic implies that you are likely to be less "tolerant" of leaks early on in the retrieval campaign, than you will be during later stages of the effort

Using the current baseline method for leak detection, considerable time may pass before the occurrence of the leak is confirmed. If a high rate of leakage is indicated, the preferred operational response may be different than in the case of a low rate of leakage. The appropriate response for a high leakage rate may be to pump out the tank as quickly as possible and rely on other technologies to support (eventual) cleanout of the tank. In the case of a low rate of leakage, or where the leakage threshold is high, the appropriate action may be to continue sluicing at the highest rate possible, and use LDMM to confirm that the leakage does not exceed threshold values. However, for each LDMM system there will also be a range of leakage volumes and/or locations for which the system is incapable of detection of the leaks due to sensitivity limits of the equipment. The rate of leakage may also be too large for candidate operational responses to have any effect. 


\section{APPENDIX B: PREVIOUS STUDLES AND FINDINGS RELATED TO LDMM}

Several studies have been performed during the past few years to support the technical basis for this strategy for LDMM. Those studies are summarized in the sections that follow. The findings from these efforts include the following:

- No externally applied technical devices, or methods, have been identified that can detect a leak of waste from a SST, (1) within the required time frame of planned sluicing/retrieval operations, and (2) when applying SST and tank farm physical and operations conditions (PNL-1994, PNL-1995, FW-1996).

- Discovering and developing a leak detection tool is not enough to solve the detection problem. Operational constraints must be applied to determine if the data from the candidate tool will be useful within the time frame of waste retrieval/sluicing operations (FW-1996, ARES-1996).

- A "perfect", available, and deployable (according to the established functions and requirements for LDMM) leak detection tool is of no value if operations has no response that can be used to address the data (FW-1996, ARES-1996).

- Deployment of a detection device presents an equally difficult challenge to getting the technique to work in a test situation/condition. The capability to deploy a device or technique is part of the LDMM functions and requirements (PNL-1995, FW-1996)

- Even when all other conditions for leak detection have been considered regarding a candidate device or method, a final decision element must be applied: risk reduction/cost benefit. If a tool is perfect for the job, that is not enough. If it is found to be only slightly greater in impact to risk reduction and contribution to decision making than the current base case methods/devices, then pursuit of the tool is not justified (FW-1996).

Table B-1 provides a summary of the scope and findings of LDMM reports and studies conducted to support development of the LDMM Strategy Document. 
Table B-1: Summary of Scope for LDMM Supporting Documentation

\begin{tabular}{|l|l|}
\hline PNL-1994 & $\begin{array}{l}\text { LDMM technology survey that identified all known/current technologies and methods and screened } \\
\text { total down to those applicable to Hanford SST LDMM conditions. Evaluates } 33 \text { remaining candidate } \\
\text { LDMM technologies including those employing electrical, seismic, radar, moisture sensor, } \\
\text { radiochemical, tracer gas detection. }\end{array}$ \\
\hline PNL-1995 & $\begin{array}{l}\text { LDMM candidate technology survey that further studied seven of the [initial] } 33 \text { technologies against } \\
\text { the LDMM functions and requirements. }\end{array}$ \\
\hline FW-1995 & $\begin{array}{l}\text { Qualitative assessment that identified factors impacting risk reduction and cost-benefit from the } \\
\text { seven leak detection technologies (i.e., mass balance (baseline method for LDMM), tracer gas, two } \\
\text { variations of Electrical Resistance Tomography (ERT), borehole logging, Time Domain } \\
\text { Reflectometry (TDR), and leak detection pits. Only mass balance is considered as available and } \\
\text { deployable. Identified programmatic and "uncontrollable" factors related to the implementation of } \\
\text { LDMM. }\end{array}$ \\
\hline $\begin{array}{l}\text { WHC-1995 } \\
\text { WHC-1996 }\end{array}$ & $\begin{array}{l}\text { The F\&Rs covered leak rate, leak volume/size, spurious indications, operating conditions, } \\
\text { deployment, availability, and response. }\end{array}$ \\
\hline FW-1996 & $\begin{array}{l}\text { The LDMM trade study covered leak detection using the seven candidate technologies identified in } \\
\text { PNL-1995; leak monitoring using ERT, borehole logging, and TDR; and leakage mitigation by } \\
\text { applying operational controls and, equipment design and availability. }\end{array}$ \\
\hline ARES-1996 & $\begin{array}{l}\text { Described the operations response to leakage that could maintain leakage below/within an } \\
\text { established envelope by minimizing in-tank liquid level, using controlled sluicing action (tank } \\
\text { sidewall and bottom last), sluicing expeditiously, minimizing equipment down-time, using available } \\
\text { in-tank surveillance tools (closed-circuit TV, flow rate measurement, liquid level measurement), and } \\
\text { by visually assessing/confirming liquid level and in-tank conditions during normal and planned } \\
\text { operational shutdowns. }\end{array}$ \\
\hline
\end{tabular}

\section{B.1 Functions and Requirements for LDMM}

The first document to evaluate the technical and operational requirements for LDMM, to support SST waste retrieval, was the LDMM functions and requirements (F\&R) report prepared in FY1995 (WHC-1995). This document identified applicable or relevant and appropriate requirements (ARARs) for specific volumes of leakant, and also introduced the concept of a leakage threshold value (LTV). (It should be noted that preparation of initial LTV estimates fulfilled TPA milestone M45-08-T01) In addition to LTV values, the F\&Rs also provided enabling assumptions, operational constraints, and potential methodologies to determine the risks presented by SST leaks.

The first version (Revision 0 ) of this document not only presented the first systems engineeringbased evaluation of LDMM, but also served as a technical starting point for evaluation of candidate LDMM technologies and operational conditions in which such technologies would have to work. The F\&Rs for LDMM cited applicable regulatory and operational requirements without confirming the existence of such tools or methods. Later, follow-on work (FW-1996a and FW1996b) investigated the current status of LDMM technology to potentially support these F\&Rs.

A second version (Revision 1) of the LDMM F\&Rs was prepared after, 1) having surveyed existing and candidate technologies, 2) performed an alternatives evaluation, and 3) reevaluating the operational conditions, requirements, and constraints cited in the first version. This second 
revision (FY-1996a) incorporated the findings of all documents, studies, and LDMM-related activities since the first version (i.e., Rev. 0 ).

The basic requirements for a "detection" device, or system were identified during the F\&R document development. The following list summarizes the requirements for LDMM tools, that were cited in the F\&R documents. These requirements were formed the technical basis for the Strategy Document:

- Determination of leak rate

- Determination of leak volume/size

- Use of proven technology/method(s) that will not produce "false positive/negative"

- Capability of functioning in SST tank farm soil and operations conditions

- Deployable within the SST tank farms as required

- Availability for immediate use to support SST waste retrieval

- Provide information within time frame of operations needs during retrieval

\section{B.2 LDMM Technology Surveys}

During FY-1994, a survey of all known leak detection and monitoring technologies was conducted by staff from the Pacific Northwest National Laboratories (PNL-1994). The objective of this work was to identify potential and existing LDMM technologies and devices that could be applied to the SST waste retrieval effort. A screening approach was applied that produced a listing of major technology "families" that were in use (e.g., electrical, seismic, radar, moisture sensor, radiochemical, tracer gas detection, etc.). The search also singled out those methods and devices that could potentially evolve into useful LDMM tools, these were classified as "candidate technologies". Thirty three available and emerging technologies were identified in the study that had the potential for external leak detection to support SST waste retrieval activities.

A second technology survey document was prepared in FY-1995 (PNL-1995) to further screen the initial listing of candidate technologies. This effort included specific physical constraints and requirements regarding deployment in Hanford SST tank farms. The screening effort was improved also by experience and information gained while demonstrating and evaluating LDMM technologies, in the field, at Hanford from FY-1994 through FY-1996. The second study evaluated all currently known technologies, including those candidate selections from the first study, plus new potential methods and devices that could be applied from within SSTs. All of these technologies were considered potentially capable of supporting the LDMM functions and requirements. The evaluation recommended a LDMM technology “toolbox" for retrieval. The focus of this study was on those devices and techniques that could support waste retrieval operations that used the design basis (high-volume/low-pressure) hydraulic sluicing method. 


\section{B.3 Technology Issues Related to SST LDMM}

A qualitative study (FW-1995) was prepared to assess potential risk reduction and cost-benefit that could be realized from deployment of leak detection technologies. LDMM topics, issues, and terminology were discussed in order to develop consistency in understanding and use. Data and findings from earlier LDMM technology survey documents were combined to determine if leak detection technologies could be expected to cost-effectively mitigate future risks that could arise from leakage during SST waste retrieval. Leakage mitigation options, that could support the retrieval process along with operational leakage response strategies and procedures, were also discussed. This study focused attention on the role of operations, and on the selection and use of leak detection tools. The follow-on effort to this task was the operations response report (ARES1996), that addressed these issues and developed a concise, procedural approach to determining if leakage occurs and initiating a risk-based response. This study also served as a technical and reference basis for the FY-1996 LDMM trade study.

Several factors were identified in the study that impact the applicability of LDMM to support SST waste retrieval operations:

- Programmatic factors: factors under the control of, or requiring decisions by, the retrieval program (e.g., threshold/allowable leakage values, retrieval method applied, operational [leak] response strategy, tank closure strategy)

- Leak factors: uncontrollable factors related to the characteristics of a tank leak (e.g., leakage rate, volume, contaminant concentrations, location, timing)

- Site factors: uncontrollable factors not directly related to a tank leak (e.g., upgradient sources of contamination, post-retrieval leakage inventory (tank basis), post retrieval leakage inventory (tank farm basis), site geology)

\section{B.4 Trade Study and Alternatives Evaluation for LDMM Technology}

A trade study was prepared (FW-1996) during FY-1996 to incorporate the findings and experience from all ongoing and previous LDMM-related activities into an evaluation of candidate technologies. The study identified and evaluated alternative approaches to LDMM in terms of cost and risk. The selected alternatives were limited to those capable of supporting SST waste retrieval operations. The results presented risk factors showing the relative performance of alternatives in terms of technology, environmental, public, worker, and accident risks. Cost assessments included consideration for technology readiness, capital, labor, disposal, and decontamination and decommissioning. These factors were then used in a decision analysis that produced a ranking of alternatives based on the current set of Hanford TWRS program values. An analysis and summary of cost-benefit was produced and a sensitivity analysis was prepared. The following major findings were presented in the LDMM Trade Study:

- Regarding leak detection - Seven LDMM technologies were identified from prior technology survey efforts (PNL-1994 and PNL-1995), and were evaluated against the LDMM F\&Rs (FW-1996a). These technologies included mass balance (baseline method for LDMM), tracer gas, two 
variations of Electrical Resistance Tomography (ERT), borehole logging, Time Domain Reflectometry (TDR), and leak detection pits. A "noaction" alternative was also included in the evaluation. Excluding leakage detection pits (that are only provided in a few specific tanks, and which can not be retrofitted), mass balance and ERT leakage detection technologies are the only methods applicable or potentially applicable to support pastpractice sluicing. Only mass balance is considered as available and deployable.

- $\quad$ Regarding leakage monitoring - Three LDMM technologies were identified that meet or potentially meet the requirements for leakage monitoring (specifically the ability to identify the location and movement of a leakage plume). These technologies were ERT, borehole logging, and TDR. Of these, only borehole logging is available and deployable at the Hanford Site. Both ERT and TDR have the potential to perform as monitoring tools to support SST waste retrieval/sluicing, however, neither has been demonstrated at Hanford or under tank farm operating conditions. Only TDR has a previous history of commercial use for leakage plume monitoring.

- Regarding leakage mitigation - The trade study concluded that only operational technique(s) and procedures employed during past-practice sluicing (which is the baseline retrieval technology for tanks that have not previously leaked) is available, deployable, and proven reliable for leakage mitigation. Planned equipment and procedural enhancements are expected to further improve waste retrieval rates using past-practice sluicing. This will reduce the sluicing time frame during which leakage can occur, thereby reducing overall leakage and public health risk. The limited sluicing alternative, which is based on fundamental mechanical principles but has not been demonstrated in an SST, may prove to be effective in mitigating leakage. Robotic sluicing and mechanical retrieval may reduce leakage and associated risk by limiting the amount of drainable water in a tank. However, these technologies are not available and are unproven for applications similar to retrieval of waste from SSTs.

\section{B.5 Operations Response to Leakage During Sluicing}

The document ARES-1996 specifically evaluated the operational activities associated with the retrieval of wastes from SSTs as proposed under the ISSTRS. Historical data were reviewed regarding previous and ongoing SST leakage, and currently available and candidate LDMM technologies were considered. The main focus of the document was to evaluate the use of available LDMM methods that could minimize leakage during retrieval/sluicing by using effective leak prevention, detection, and mitigating actions. The report defines options for responding to indications of leakage that occur during waste retrieval/sluicing activities, using currently available technology. This document incorporates the findings of the LDMM F\&Rs (WHC-1995 and FW1996a), the candidate LDMM technology surveys (PNL-1994 and PNL1995), and the LDMM Technology Trade Study (FW-1996b). 
The report concludes that currently available, in-tank, level measurement devices and techniques should be applied to determine if leakage is occurring during sluicing. The report further concludes that the only currently available leak detection method that can detect a leak within a reasonable leakage volume, and within a time frame consistent with planned sluicing operations, is the mass balance system. Implementation of the operational sequence of sluicing activities, presented in this report, will minimize the probability and volume of leaks by keeping liquid away from [in-tank] locations that are believed to have the greatest potential for leaking. Specific operational responses were identified which could be used in conjunction with the planned sluicing sequence and leak detection methods to minimize worker exposure and environmental, safety, and health risks. The following specific actions were recommended to achieve the goal of MPAL during retrieval:

- Refine tank waste data to develop final LTVs for selected tanks

- Approve operational planned responses, on a tank-by-tank basis, and have equipment available to support recommended actions

- $\quad$ Establish refined leakage level limits, on a tank-by-tank basis, using guidelines detailed in the report

- Complete detailed retrieval procedures specific to each tank

- Identify tanks for inclusion within the ISSTRS scope, focusing on selection of sound, non-leaking tanks that can be readily sluiced

- Continue efforts to identify and develop better leak detection technologies

If the recommended actions are followed, the report concludes that the probabilities of leakage occurring during sluicing are minimized, and there is greater assurance that, should leaks occur during SST waste retrieval, they can be managed to minimize any increased risk to the public. Other ISSTRS-related activities and design features that could also be employed to contribute to the goals of MPAL, cognizance of leakage events, and improved response capability. The following list summarizes these recommendations:

- $\quad$ Sluice expeditiously to reduce the likelihood and size of potential leaks.

- ISSTRS equipment design, and availability during operations, should minimize the potential for maintenance and outage down time during sluicing.

- Utilitze all currently available leakage "surveillance" tools (e.g., CCTV, flow rate measurement, liquid level measurement, etc.) to the greatest extent practical during sluicing.

- Utilize and incorporate new LDMM technologies, and enhancernents to current tools and methods, as they become available. 
- Minimize liquid addition during sluicing to the greatest extent practical.

- Use planned, non-sluicing operational periods/pauses to visually assess sluicing effectiveness and to conduct waste/solids level estimates as part of the mass balance method leakage determination method (Stopping specifically for liquid level estimates will slow down retrieval operations, increasing the likelihood of a leak, and is not recommended).

\section{B.6 LDMM Technology Field Testing and Demonstrations at Hanford}

During the period from FY-1994 through FY-1996, a cooperative effort between DOE-RL, DOE-HQ, WHC, Lawrence Livermore National Laboratories (LLNL), and technology providers, has been ongoing. Field testing, demonstration, and evaluation of candidate leak detection and monitoring technologies has been performed using a mock tank test site that was constructed within the 200 East area of the Hanford Site. Activities at the test site provided a realistic "laboratory" in which to deploy prototype sensors, conduct simulated leakage event testing, and to evaluate the potential impacts of Hanford soil conditions on equipment and results. These activities provided an opportunity to determine the potential impacts and implications of actual operational conditions on the deployment and use of candidate technologies for leak detection. Most of the insights into the required functions and requirements, and operational constraints related to leak determination, were derived from field activities and test findings observed during these efforts.

Testing and technology development is ongoing through FY-1996 with work on a sensor deployment capability using the cone penetrometer technique (CPT). The findings and planned work in this subject is focused on developing a usable leakage detection or monitoring capability for use to support SST sluicing waste retrieval. Development of prototype ERT electrodes, using CPT, is planned for FY-1996. If CPT is shown to be capable of deploying candidate leak detection and monitoring sensors, such as ERT, into the appropriate areas around SSTs and in tank farms, then the possibility will exist to introduce future technologies for use when and if they become available. Improved capability to deploy and operate monitoring and detecting tools externally to SSTs could reduce the operational response time to leakage, thus reducing risk of damage to the environment from large leaks. 
Proposed Strategy for LDMM During Hanford SST Waste Retrieval (WHC-SD-WM-ES-378, Rev 0)

APPENDIX C: LDMM CRITERIA FOR DETERMINING ALLOWABLE LEAKAGE 


\section{LDMM Criteria for Determining Allowable Leakage}

WHC-SD-WM-ES-392, REV. 0

May 24, 1996

\section{Prepared for}

Westinghouse Hanford Company

Tank Waste Remediation System

Task 021 of Order No. MGK-SVV-186918

\section{Prepared by}

Foster Wheeler Environmental Corporation 1981 Snyder Road, Suite 3

Richland, WA 99352 
WHC-SD-WM-ES-378, Rev 0

(Reference WHC-SD-WM-ES-392, Rev. 0)

This page intentionally left blank. 


\section{WHC-SD-WM-ES-378. Rev 0 \\ (Reference WHC-SD-WM-ES-392, Rev. 0)}

\section{ACRONYMS AND ABBREVIATIONS}

$\begin{array}{ll}\text { COC } & \text { constituents of concern } \\ \text { DOE } & \text { U.S. Department of Energy } \\ \text { DST } & \text { double-shell tank } \\ \text { Ecology } & \text { Washington State Department of Ecology } \\ \text { EIS } & \text { Environmental Impact Statement } \\ \text { ERT } & \text { electrical resistivity tomography } \\ \text { ILCR } & \text { incremental lifetime cancer risk } \\ \text { LDMM } & \text { leakage detection, monitoring, and mitigation } \\ \text { MCL } & \text { Maximum Contaminant Level } \\ \text { MEI } & \text { maximally exposed individual } \\ \text { RCRA } & \text { Resource Conservation and Recovery Act } \\ \text { SST } & \text { single-shell tank } \\ \text { Tri-Party } & \\ \text { Agreement } & \text { Hanford Federal Facility Agreement and Consent Order } \\ \text { TWRS } & \text { Tank Waste Remediation System }\end{array}$


WHC-SD-WM-ES-378, Rev 0

(Reference WHC-SD-WM-ES-392, Rev, 0)

This page intentionally left blank. 


\section{TABLE OF CONTENTS}

1.0 INTRODUCTION AND BACKGROUND $\ldots \ldots \ldots \ldots \ldots \ldots \ldots \ldots$

2.0 SUMMARY OF ALLOWABLE LEAKAGE DETERMINATION STRATEGY . . . 2-1

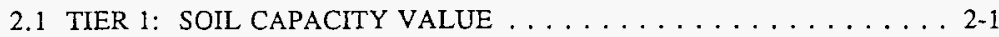

2.1.1 Fate of Leakage From SSTs . . . . . . . . . . . . . 2-2

2.1.2 Calculation of Soil Capacity Value .............. 2-2

2.2 TIER 2: MAXIMUM POTENTIAL LEAKAGE . . . . . . . . . . . 2-3

2.2.1 Calculation of Maximum Potential Leakage . . . . . . . . . . . 2-3

2.3 TIER 3: MINIMUM PRACTICABLE ACHIEVABLE LEAKAGE . . . . . . 2-4

3.0 ALlowABLE LEAKAGE CRITERIA $\ldots \ldots \ldots \ldots \ldots \ldots \ldots \ldots \ldots$ 3-1

3.1 CRITERION 1 - CONTROLLING RISK SCENARIO . . . . . . . . 3-2

3.1.1 Importance of Criterion . . . . . . . . . . . . . 3-2

3.1.2 Criterion Recommendation . . . . . . . . . . . . 3-2

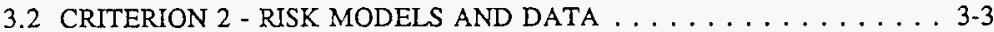

3.2.1 Importance of Criterion . . . . . . . . . . . . . 3-3

3.2 .2 Criterion Recommendation . . . . . . . . . . . 3-3

3.3 CRITERION 3 - POINT OF COMPLIANCE . . . . . . . . . 3-4

3.3 .1 Importance of Criterion . . . . . . . . . . . . 3-4

3.3.2 Criterion Recommendation . . . . . . . . . . . . . 3-4

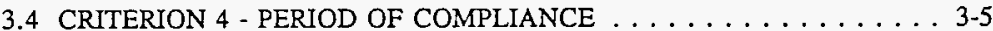

3.4.1 Importance of Criterion . . . . . . . . . . . . 3-5

3.4.2 Criterion Recommendation . . . . . . . . . . . . 3-5

3.5 CRITERION 5 - CONSTITUENTS OF CONCERN $\ldots \ldots \ldots \ldots \ldots$

3.5.1 Importance of Criterion . . . . . . . . . . . 3-6

3.5 .2 Criterion Recommendation . . . . . . . . . . . . . 3-6

3.6 CRITERION 6 - VADOSE ZONE FLUX DISTRIBUTION $\ldots \ldots \ldots$ 3-7

3.6.1 Importance of Criterion . . . . . . . . . . . 3-7

3.6.2 Criterion Recommendation . . . . . . . . . . . 3-7

3.7 CRITERION 7 - ALLOWABLE RISK $\ldots \ldots \ldots \ldots \ldots \ldots \ldots \ldots$ 3-8

3.7.1 Importance of Criterion . . . . . . . . . . . . 3-8

3.7 .2 Criterion Recommendation . . . . . . . . . . . . 3-8

3.8 CRITERION 8 - TANK SOURCES OF RISK . . . . . . . . . . 3-9

3.8 .1 Importance of Criterion . . . . . . . . . . . . 3-9

3.8 .2 Criterion Recommendation . . . . . . . . . . . . . 3-9

3.9 CRITERION 9 - LEAKAGE CONCENTRATIONS . . . . . . . 3-10

3.9.1 Importance of Criterion . . . . . . . . . . . . . . 3-10

3.9.2 Criterion Recommendations . . . . . . . . . . . 3-10

3.10 CRITERION 10 - ACCEPTABLE CLOSURE OPTIONS . . . . . . 3-11

3.10 .1 Importance of Criterion $\ldots \ldots \ldots \ldots \ldots \ldots \ldots \ldots$ 3-11

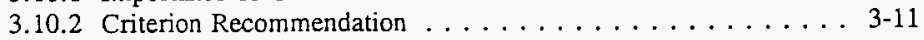




\author{
WHC-SD-WM-ES-378, Rev 0 \\ (Reference WHC-SO-WM-ES-392. Rev. 0)
}

TABLE OF CONTENTS (cont'd)

3.11 CRITERION 11 - LEAKAGE VOLUMES . . . . . . . . . . 3-12

3.11 .1 Importance of Criterion $\ldots \ldots \ldots \ldots \ldots \ldots \ldots \ldots \ldots .12$

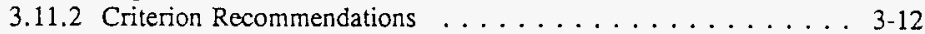

3.12 CRITERION 12 - ALIGNED WASTE SOURCES . . . . . . . 3-13

3.12.1 Importance of Criterion . . . . . . . . . . . . . . 3-13

3.12.2 Criterion Recommendation . . . . . . . . . . . . 3-13

3.13 CRITERION 13 - RISK APPORTIONMENT . . . . . . . . . 3-14

3.13 .1 Importance of Issue $\ldots \ldots \ldots \ldots \ldots \ldots \ldots . \ldots \ldots$ 3-14

3.13.2 Criterion Recommendation ... . . . . . . . . . 3-14

3.14 CRITERION 14 - LEAKAGE DETECTION TECHNOLOGY . . . . . 3-15

3.14 .1 Importance of Criterion . . . . . . . . . . . . . 3-15

3.14.2 Criterion Recommendation . . . . . . . . . . . . . 3-15

3.15 CRITERION 15 - LEAKAGE MITIGATION TECHNOLOGY . . . . . 3- 3-16

3.15 .1 Importance of Criterion . . . . . . . . . . . . 3-16

3.15 .2 Criterion Recommendations . . . . . . . . . . 3-16

3.16 CRITERION 16 - INDIVIDUAL TANK CHARACTERISTICS . . . . 3-17

3.16 .1 Importance of Criterion . . . . . . . . . . . 3-17

3.16 .2 Criterion Recommendation . . . . . . . . . . . 3-17

3.17 CRITERION 17 - EXCEEDANCE OF ALLOWABLE LEAKAGE

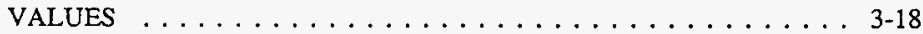

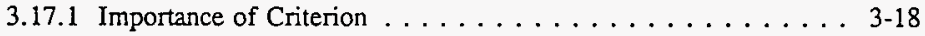

3.17.2 Criterion Recommendation . . . . . . . . . . . . 3-18

3.18 CRITERION 18 - EXCEEDANCE OF LEAKAGE CEILINGS . . . . . 3-19

3.18.1 Importance of Criterion . . . . . . . . . . . . 3-19

3.18.2 Criterion Recommendation . . . . . . . . . . . . . 3-19

3.19 CRITERION 19 - ABSOLUTE LIMIT ON ALLOWABLE LEAKAGE . . 3-20

3.19 .1 Importance of Criterion . . . . . . . . . . . . 3-20

3.19.2 Criterion Recommendation . . . . . . . . . . . . . 3-20

4.0 EXAMPLE PROCESS FOR DERIVING ALLOWABLE LEAKAGE VALUES . . . 4-1

4.1 PRELIMINARY ALLOWABLE LEAKAGE VALUES $\ldots \ldots \ldots \ldots \ldots$. . . .

4.2 ADJUSTED ALLOWABLE LEAKAGE VALUES . . . . . . . 4 4-3

5.0 SUMMARY OF CRITERIA RECOMMENDATIONS REQUIRING

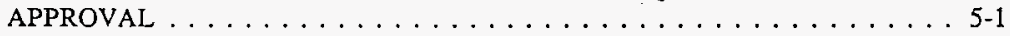

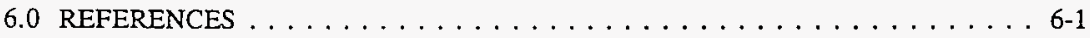

\title{
LIST OF TABLES
}

3-1 Allowable Leakage Criteria and Associated Issues $\ldots \ldots \ldots \ldots$ 3-1 . . . . . .

4-1 Hypothetical Preliminary Allowable Leakage Criteria . . . . . . . . . . . 4-3

5-1 Summary of Criteria Recommendations . . . . . . . . . . . . 5-1 


\author{
WHC-SD-WM-ES-378, Rev 0 \\ (Reference WHC-SD-WM-ES-392. Rev. 0)
}

\title{
1.0 INTRODUCTION AND BACKGROUND
}

The M-45 series of Hanford Federal Facility Agreement and Consent Order (Tri-Party Agreement) milestones address leakage from single-shell tanks (SSTs) during waste retrieval. Tri-Party Agreement milestone M-45-08-T02 specifies that, "criteria for determining allowable leakage volumes, and acceptable leakage monitoring, detection, and mitigation measures necessary to permit sluicing operations" be approved by the Washington State Department of Ecology (Ecology). To meet this milestone, the U.S. Department of Energy (DOE) and its contractors will (1) develop the background and basis for a criteria decision, (2) propose appropriate criteria and measures for leakage detection, monitoring, and mitigation (LDMM), and (3) establish an agreement with Ecology regarding the issues and recommendations. This document addresses item 2, propose appropriate criteria and measures for LDMM.

The allowable leakage from a single-shell tank during new sluicing operations should be based on relevant regulatory, policy, and technical criteria. These criteria are measures or approaches (to resolve questions/issues) that will provide a basis for making decisions regarding LDMM and allowable leakage during SST waste retrieval. The criteria should be supported by accepted and/or approved enabling assumptions and data. There are significant issues, assumptions, and data related to each criterion. Resolution of issues will require policy decisions or guidance, and improved data in some cases. The following sections identify the larger issues and make recommendations regarding reasonable assumptions and data needs.

Section 2 provides a summary of the LDMM operational strategy and introduces a graded or tiered approach to establish allowable leakage values. Section 3 identifies preliminary criteria and recommendations for resolving issues that may impact the level of allowable leakage. Section 4 gives an example of a proposed process for determining preliminary allowable leakage values for planning purposes and a hypothetical example of how these values would change as tank waste retrieval proceeds. The key criteria and recommendations are summarized in Section 5. 
WHC-SD-WM-ES-378, Rev 0

(Reference WHC-SD-WM-ES-392, Rev. 0)

This page intentionally left blank. 


\section{WHC-SD-WM-ES-378, Rev 0 \\ (Reference WHC-SD-WM-ES-392. Rev. 0)}

\subsection{SUMMARY OF ALLOWABLE LEAKAGE DETERMMNATION STRATEGY}

Past-practice sluicing has been selected as the method that will be used to remove saltcake and sludge waste from Hanford Site SSTs. Three IDMM concems during sluicing are (1) determining when a leakage "event" has occurred, (2) ensuring adequate surveillance of existing or new leak plumes, and (3) taking responsible retrieval actions that minimize the potential for leakage to occur. These concerns will be addressed through appropriate operational responses and the use of devices for leakage detection, leakage plume monitoring, and leakage mitigation. Retrieval operations will apply current LDMM measures to maintain leakage at the lowest levels practicable and below allotted leakage ceilings. Establishment of [allowable] operational leakage parameters will be achieved by risk-based decision making applied to a set of criteria. Allowable leakage criteria have been identified and prioritized for consideration within the decision-making process. All of the criteria fall into a sequence or path to establishing the allowable leakage volume. This path consists of the following steps:

- Enabling assumptions are made

- Required data are obtained and reviewed

- Issues are addressed to a "concluding point"

- Decisions are made

- Criteria are developed to a clear statement and are closed

- The criteria are sequentially addressed, resulting in preliminary allowable leakage volumes

- The assumptions and data are reviewed and the allowable leakage volumes revised as waste retrieval proceeds.

Three major tiers have been recommended to establish allowable leakage values: (1) site-specific soil moisture retention capacity, (2) maximum potential leakage due to retrieval by sluicing, and (3) leakage constraints that will be imposed upon operations during actual retrieval/sluicing activities. This three-tiered approach to defining leakage boundaries is discussed in the following sections.

\subsection{TIER 1: SOIL CAPACITY VALUE}

At Tier 1 a combination of historical and theoretical data will be evaluated and compared with vadose zone modeling data to produce a bounding value for the retention capacity of leakage in the soil beneath a target tank and/or tank farm. This value represents the highest volume of liquid waste (maximum tolerable leakage) that could be expected to penetrate into the surrounding soil to a depth that would not render impractical the 


$$
\begin{gathered}
\text { WHC-SO-WM-ES-378, Rev } 0 \\
\text { (Reference WHC-SD-WM-ES-392, Rev, 0) }
\end{gathered}
$$

remediation of unacceptable contamination resulting from the leakage. The modeling applied for this decision would include consideration of existing leakage plumes, and local soil and hydrology characteristics. This volume provides the first level of maximum tolerable leakage volume. Leakage of this magnitude would have a high potential to impact the groundwater within several decades if not remediated, and would substantially contaminate the soil in and around the target tank.

\subsubsection{Fate of Leakage From SSTs}

Leakage that occurs from SSTs will pass through the pore spaces between soil particles and migrate laterally and downward due to the force of gravity and the stratigraphic, anisotropic, and other physical characteristics of the soils. The resulting plumes will generally be ellipsoidal and elongated in the horizontal direction. A newly created plume will spread in the soil rather quickly when leakage first occurs. Its growth will diminish when the water has spread to the point that the plume water becomes restrained in the soil capillaries. The plume will then migrate very slowly toward the water table. Downward plume migration rates depend on (1) recharge (the amount of precipitation that infiltrates the soil after subtracting evaporation and transpiration by plant roots) and (2) the physical characteristics of the soil that control the ability of the soil to retain water. These rates can vary from about 1 in. per year to more than $35 \mathrm{ft}$ per year for the different water contents and soil types found beneath the Hanford Site 200 Areas tank farms.

An example of the fate of leakage from an SST is Tank 241-T-106, which leaked $115,000 \mathrm{gal}$ in 1973. This is the largest tank leakage experienced to date at the Hanford Site. The leakage from this tank formed a generally static plume about $180 \mathrm{ft}$ long, $160 \mathrm{ft}$ wide, and 70 to $90 \mathrm{ft}$ deep. Leakage investigations in 1979 indicated that the leakage was located at least $95 \mathrm{ft}$ above the water table. Later monitoring in 1993 and 1994 indicated that the base of the plume was about $75 \mathrm{ft}$ above the water table. These results cannot be directly compared because they are based on monitoring of different radionuclides; however, they do provide support to the concept of a relatively large soil leakage retention capacity and a relatively slow migration rate.

\subsubsection{Calculation of Soil Capacity Value}

Tank razing and soil excavation are the assumed remedial actions that would be taken for mitigating leakage when the leakage ceiling established to enable the most cost-effective closure approach is exceeded. There are practical limits to these actions, based on worker risk and cost, number of tanks razed, soil volume excavated, and depth of soil excavation. The moisture retention capacity of the soil and the leakage plume's rate of downward movement are dependent on the properties of the soil. The allowable time period from the original leak until mitigative actions are completed must be established.

Based on a cursory review of data on site soil beneath the Hanford Grout Facility, it is estimated that the soil can hold an additional 8 vol\% or more of moisture before its matric 


$$
\begin{gathered}
\text { WHC-SD-WM-ES-378, Rev } 0 \\
\text { (Reference WHC-SD-WM-ES-392, Rev, 0) }
\end{gathered}
$$

potential would increase to a level above $-10 \mathrm{~cm}$ water. Water will freely drain in soil at a matric potential of about zero or higher. The base of many of the SSTs are approximately $150 \mathrm{ft}$ above the aquifer. If the plume cross-section is assumed to be equal to the tank footprint and to extend halfway to the aquifer, the soil leakage capacity value is $200,000 \mathrm{gal}$ or larger, based on a minimum moisture increase of $8 \mathrm{vol} \%$. This is in rough agreement with the Tank 241-T-106 leakage data described in Section 2.1.1. This value is compared with the maximum potential leakage volume (Tier 2) described in Section 2.2.

\subsection{TIER 2: MAXIMUM POTENTIAL LEAKAGE}

A comparison between the volume of a maximum potential leakage that could occur from a target tank due to a retrieval action such as sluicing (Tier 2), and the Tier 1 soil capacity value should be made. The Tier 2 maximum potential leakage would occur if the leakage detection and response system failed to detect and mitigate catastrophic leakage that occurred near the beginning of retrieval operations. The difference between Tier 1 and Tier 2 leakage values provides a measure of the effectiveness of the soil beneath the tank to ensure interim protection of the groundwater, if the maximum leakage were to occur. Even though the potential for the occurrence of maximum volume leakage (Tier 2) is very small, there is no way to guarantee against it. This is due to the lack of significant and absolute control over leakage once it occurs, and the inaccuracy with which leakage can be detected using currently available technology. Therefore, the risks associated with this maximum volume of leakage must be judged "acceptable" before proceeding with sluicing.

\subsubsection{Calculation of Maximum Potential Leakage}

The SST slurry pump and the double-shell tank (DST) sluice pump flow rates will be matched during sluicing to continually maintain a head of liquid over the slurry pump intake. A major leak in the SST in this case would lower the head in the slurry pump and cause the pump to cavitate, signalling potential leakage to the operators. The sluicing system would be shut down with no further liquid added to the SST. The volume of liquid that could leak if a catastrophic leak were to occur at this point is the liquid head at the pump intake plus the drainable liquid contained in the waste. The maximum leakage would occur if the catastrophic leak happened near the beginning of the retrieval operation when the waste volume is at a maximum and when the pump intake is submerged in liquid.

Two cases of maximum potential leakage were evaluated based on data from the Waste Tank Summary Report for the Month Ending October 31, 1995 (Hanlon 1995). These include an upper bounding case and an average case. The upper bounding case is a tank nearly full of saltcake waste (i.e., Tank 241-A-101, which contains 950,000 gal of saltcake). Much of the liquid held in the saltcake waste can be assumed to drain, whereas sludge waste has small particle sizes and will tend to hold the interstitial liquid tightly (i.e., it has a high capillarity). The average SST contains 156,000 gal of saltcake waste and 79,000 gal of sludge waste. 


\author{
WHC-SD-WM-ES-378, Rev 0 \\ (Reference WHC-SD-WM-ES-392, Rev. 0)
}

A reasonable assumption is that the retrieval system is operated to maintain a $2-\mathrm{ft}$ head of liquid above the SST slurry pump intake. This equates to 66,000 gal of liquid in a 75 -ft diameter tank. The volume of drainable liquid for the Tank 241-A-101 upper bounding case is given in Hanlon (1995). The ratios of drainable liquid to total waste for saltcake and sludge waste can be derived from Tank 241-A-101 data in Hanlon (1995). Applying these ratios to the average case and adding the 66,000 gal from the assumed liquid head gives the following result. The potential upper bounding case leakage is provided for comparison.

Average Case

Upper Bounding Case (Tank 241-A-101)
$140,000 \mathrm{gal}$

$480,000 \mathrm{gal}$.

\title{
2.3 TIER 3: MINIMUM PRACTICABLE ACHIEVABLE LEAKAGE
}

The Tier 1 analysis established the maximum volumes of leakage allowable to ensure interim protection of the groundwater. In most cases the maximum potential leakage determined in the Tier 2 analyses will be less than Tier 1 levels. Lower levels of allowable leakage (Tier 3 ) will be imposed to create an even greater degree of protection. The Tier 3 levels serve as constraints within which retrieval actions can proceed. Tier 3 leakage limits will be imposed as a means of optimizing potential for cost-effective and compliant closure of the tanks following sluicing. Actions that will help attain these limits and the goal of minimum practicable achievable leakage include ordering the tanks for retrieval based on the potential leakage risks, availing a range of pre-approved operational leakage response actions, enhancing design of the sluicing equipment, modifying current operations procedures and decision-making plans, and making maximum use of currently available technologies and methods.

The allowable leakage criteria associated with the three-tiered approach to defining leakage boundaries are discussed in greater detail in Section 3. 


\section{WHC-SD-WM-ES-378, Rev 0 \\ (Reference WHC-SD-WM-ES-392, Rev. 0)}

\subsection{ALLOWABLE LEAKAGE CRITERIA}

The allowable leakage from an SST during new sluicing operations should be based on relevant regulatory, policy, and technical/operational criteria. The criteria should be supported by accepted and/or approved enabling assumptions and data. There are significant issues associated with the criteria and the assumptions and data. Resolution of issues will require policy decisions, guidance, and improved data. This will lead to clarification and closure of the criteria. This section identifies 19 important allowable leakage criteria and includes recommendations for the quantification and justification of each. A summary of the leakage criteria and related issues is provided in Table 3-1.

Table 3-1. Allowable Leakage Criteria and Associated Issues.

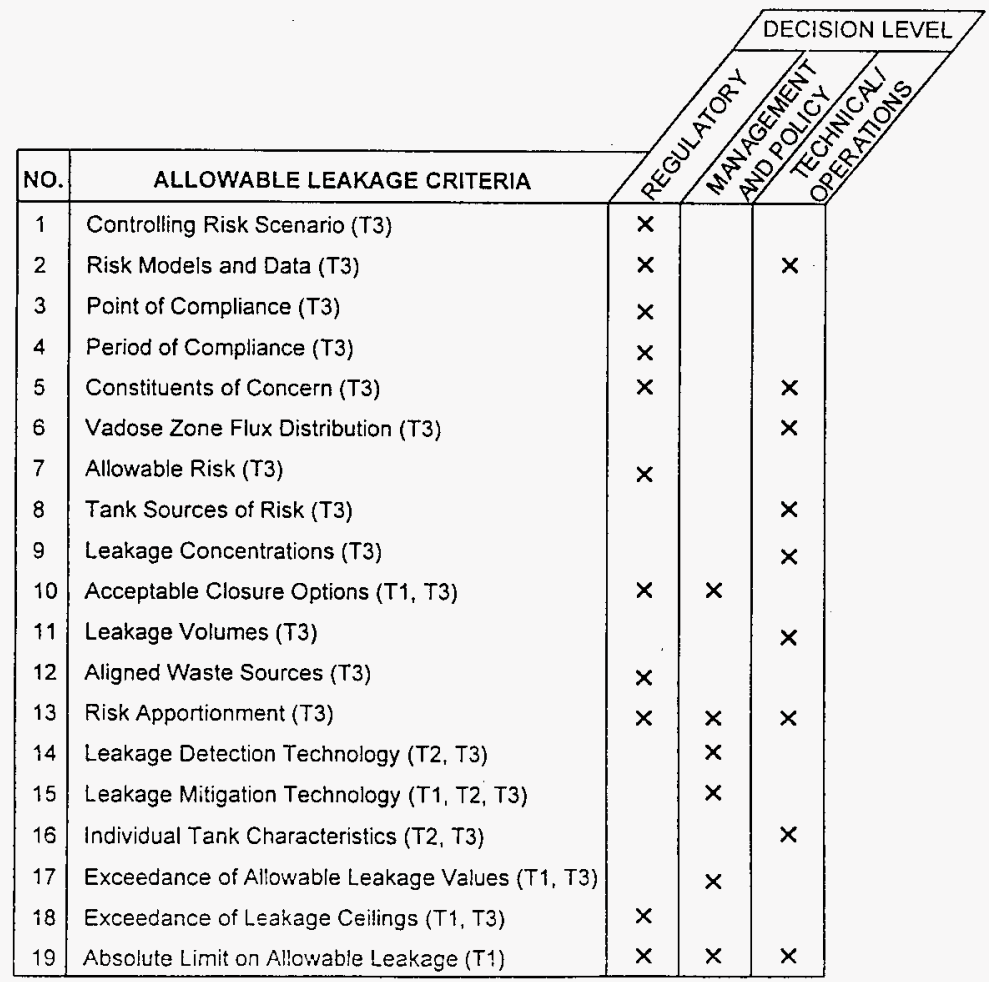

T1 = Applicable to Tier $1 \quad T 2=$ Applicable to Tier 2 T3 = Applicable to Tier 3 
WHC-SD-WM-ES-378, Rev 0

(Reference WHC-SD-WM-ES-392, Rev, 0)

\subsection{CRITERION 1 - CONTROLLING RISK SCENARIO}

Establish the controlling risk scenario to determine how much leakage is hamful.

\subsubsection{Importance of Criterion}

The controlling risk scenario must be established to provide the basis for making defensible risk-based decisions regarding potential impacts of waste leakage. Various risk scenarios are evaluated under the National Environmental Policy Act, the Comprehensive Environmental Response, Compensation, and Liability Act, the Resource Conservation and Recovery ACt (RCRA), and DOE guidance to support remedial action decision making. Common risk scenarios include those that adversely impact worker health and safety, degrade short- and long-term public health, and damage the ecology. The primary objective of most cleanup actions is to ensure long-term protection of human health. Most long-term risk analyses focus on the impacts to a maximally exposed individual (MEI) who uses contaminated groundwater or surface water. The draft Tank Waste Remediation System (TWRS) Environmental Impact Statement (EIS) focused its evaluation on the health risk to a maximally exposed onsite farmer who uses contaminated groundwater under the Hanford Site. Regulatory limits exist to protect the groundwater and users of groundwater (e.g., Maximum Contaminant Levels [MCLs]). The draft TWRS-EIS also evaluated an intruder risk scenario that showed significantly higher risks to the intruder; however, no regulatory limit is known to exist for the protection of intruders. The existence of regulatory limits for protection of groundwater supports selection of the onsite MEI farmer using contaminated Hanford groundwater as the controlling risk scenario.

\subsubsection{Criterion Recommendation}

The controlling risk scenario for SST leakage should be exposure of the MEI (onsite farmer) to contaminated drinking water from a well and to farm products grown with the same well water. The same risk exposure pathways and parameters used in the draft TWRSEIS should be used for preliminary evaluations of allowable leakage. This will enhance comparability to the TWRS analyses and promote better understanding and approval by the sponsoring agencies (Ecology and DOE). The intruder scenario should not be selected as the controlling risk scenario because no regulatory limits exist for protecting intruders. 
WHC-SD-WM-ES-378, Rev 0

(Reference WHC-SD-WM-ES-392. Rev. 0)

\subsection{CRITERION 2 - RISK MODELS AND DATA}

Establish the mathematical models, boundary conditions, and input data to be used to simulate the controlling risk scenario.

\subsubsection{Importance of Criterion}

It is necessary to establish a consistent, approved approach for using specific models, data, and boundary conditions to increase acceptance of the modeling results. Large differences in calculated risks can result when different contaminant fate and transport models and assumptions are used. The draft TWRS-EIS used (1) a congruent dissolution model to simulate release of contaminants from the tanks to the vadose zone, (2) a onedimensional advective-dispersion (no diffusion) model to simulate transport of contaminants through the vadose zone, and (3) a one-dimensional advective-dispersion model to simulate transfer of contaminants in the aquifer to the Columbia River. Adjacent tank farms were grouped into source areas in the draft TWRS-EIS. The contaminant flux from each source area was assumed to be uniformly released into a vadose-zone cell with surface dimensions of 0.6 by $0.6 \mathrm{mi}$. The flux entering the groundwater was assumed to be dispersed uniformly and vertically in the groundwater to a depth of $20 \mathrm{ft}$. The resulting groundwater plume was assumed to disperse laterally and horizontally within the constraints of established Hanford Site aquifer boundary conditions. This model is appropriate for far-field projections of risk to the MEI (onsite farmer).

Other refinements, such as (1) including past leakage in the analysis, (2) including a diffusion algorithm in the vadose zone transport model, (3) using solubility-limited release algorithms, and (4) reducing the dimensions of the vadose zone flow cells to correspond to the footprints of individual tank farms have been used in previous modeling efforts.

\subsubsection{Criterion Recommendation}

Simple one-dimensional release algorithms and transport models should be used for preliminary evaluations of allowable leakage. The same or equivalent algorithms and models used in the draft TWRS-EIS should be employed. Boundary conditions and input data should be identical. Future refinements to models and data should be clearly described and rationale for the changes should be provided. A consistent modeling approach will facilitate comparison of results and enhance defensibility of allowable leakage analyses. 


\subsection{CRITERION 3 - POINT OF COMPLIANCE}

Establish the point of compliance following closure of a tank fann.

\subsubsection{Importance of Criterion}

The point of compliance for a closed waste site is defined in a RCRA closure plan and is usually near the boundary of the waste site. Future Hanford land-use planning efforts may result in establishing a long-term waste disposal site or exclusion area that encompasses both the 200 East and 200 West Areas. The boundaries of the long-term waste site may be a mile or more downgradient from the nearest tank. Groundwater plumes generally increase in width and depth as a function of distance from the contributing waste sources. The increasing plume size is primarily caused by advective dispersion, and results in diluting the contaminant concentrations in the plume. Lower concentrations in the plume equate to lower risk. Thus, the nearer the tank farm, the higher the risk. Assumptions should be made about possible locations of boundaries and compliance points to estimate potential groundwater concentrations of constituents of concern (COCs) and associated risks.

\subsubsection{Criterion Recommendation}

The risk impacts at several potential compliance points should be evaluated to establish the sensitivity of waste site boundary locations. The risk impacts associated with residual waste in the tanks following sluicing and other significant sources such as leakage, should be added to determine cumulative risk. The cumulative risk should be compared to potential risk threshold(s) in the closure plan(s) to determine if compliance can be achieved. These risk analyses will demonstrate the relationship between compliance points and retrieval actions that impact the amount of residual tank waste and amount of leakage (and associated risk) that may occur. 
WHC-SD-WM-ES-378, Rev 0

(Reference WHC-SD-WM-ES-392, Rev. 0)

\subsection{CRITERION 4 - PERIOD OF COMPLIANCE}

Establish the period of time over which compliance must be assured.

\subsubsection{Importance of Criterion}

The COCs in Hanford Site tanks pose different risks due to differing toxicities and mobilities. Certain COCs move with the speed of water because they do not chemically sorb onto soil. Other COCs sorb to varying degrees. If a Hanford Barrier is used over tank farms as part of the closure plan, the barrier will significantly restrict water recharge. Precipitation that penetrates the barrier will not reach the water table for thousands of years. Thus, only the most mobile COCs will reach the groundwater within the 10,000 -year period of regulatory interest. If the Hanford Barrier limits recharge to less than $0.05 \mathrm{~cm} / \mathrm{yr}$, the peak flux of contaminated water to the water table may be delayed to a time after 10,000 years. For all practical purposes, the delay is not dependent on the amount of residual waste in the tanks, nor on the amount of leakage that has occurred. In theory, the Hanford Barrier can eliminate all risks to the MEI within the 10,000 year timeframe, regardless of whether waste removal actions have been taken.

\subsubsection{Criterion Recommendation}

The Hanford Barrier is a key element of the overall strategy for remediating tank farms and its effectiveness must be evaluated. Physical evidence and continuing studies may show that the barrier can limit recharge to less than $0.05 \mathrm{~cm} / \mathrm{yr}$ for more than 10,000 years, assuming barrier maintenance will be performed over that time period as necessary to ensure effective performance. The impacts to risk and compliance for this case should be evaluated over a period that captures the peak risks associated with mobile COCs. This approach is justified if future land-use decisions result in creating a secure, long-term waste disposal area that encompasses the 200 Areas. The assumption is that a secure waste disposal area would be guarded against human intrusion and maintained for as long as the disposal area is considered a threat to human health. Thus, the period of compliance should be 10,000 years, but longer if required to capture peak $C O C$ groundwater concentrations. 
WHC-SD-WM-ES-378, Rev 0

(Reference WHC-SO-WM-ES-392, Rev, 0)

\subsection{CRITERION 5 - CONSTITUENTS OF CONCERN}

Determine the components of SST waste that should be considered COCs.

\subsubsection{Importance of Criterion}

Risk analyses performed at the Hanford Site repeatedly identify the same COCs when the Hanford Barrier is employed and when the period of compliance is less than 50,000 years. The identified COCs are mobile and nonsorbing, and include ${ }^{99} \mathrm{Tc},{ }^{129} \mathrm{I},{ }^{14} \mathrm{C}$, uranium, and nitrate (including nitrite). These COCs typically contribute to greater than $95 \%$ of the cumulative carcinogenic and noncarcinogenic risks.

\subsubsection{Criterion Recommendation}

The recommended COCs are ${ }^{99} \mathrm{Tc},{ }^{129} \mathrm{I},{ }^{14} \mathrm{C}$, uranium, and nitrate. Analyzing only the most significant contributors to risk reduces cost without compromising defensibility of the analysis. 


\subsection{CRITERION 6 - VADOSE ZONE FLUX DISTRIBUTION}

Establish whether the flux of COCs released into the vadose zone from tank farm groupings should be asswned uniformly distributed within a 0.6- by 0.6-mi cell as in the draft TWRS-EIS, or be assumed as released from individual tank farms into cells approximately equal to the footprints of the individual farms.

\subsubsection{Importance of Criterion}

The radius of influence of a well sufficient to meet the drinking water and irrigation needs of a residential farm is about the width of a typical tank farm footprint (e.g., approximately $400 \mathrm{ft}$ ). Thus, if the point of compliance is near the farm, the well can theoretically capture the entire $\mathrm{COC}$ flux as it enters the groundwater. The cells evaluated in the draft TWRS-EIS are about eight times the width of a tank farm. Each tank farm cell in the draft TWRS-EIS contains two or more tank farms. Therefore, the draft TWRS-EIS approach will yield lower risk results by up to a factor of four when the point of compliance is near the tank farm. At distances of several miles, the individual plumes will converge and mix due to the effects of advective dispersion. The draft TWRS-EIS approach yields the most defensible risk values when the point of compliance is a substantial distance from the tank farms.

\subsubsection{Criterion Recommendation}

A vadose zone modeling approach should be selected that is technically consistent with assumed point(s) of compliance. Several points of compliance should be evaluated pending definition of the boundaries of a future waste disposal zone(s) that includes the tank farms. An appropriate modeling approach is warranted for near-field points of compliance. 
WHC-SD-WM-ES-378, Rev 0

(Reference WHC-SD-WM-ES-392, Rev. 0)

\subsection{CRITERION 7 - ALLOWABLE RISK}

Esrablish the allowable risk to the MEI (onsite farmer).

\subsubsection{Importance of Criterion}

Drinking water typically is the primary source of risk to the MEI. The generally accepted upper limits of risks following cleanup of waste sites are an incremental lifetime cancer risk (ILCR) of $10^{-4}$ and a hazard index of 1.0. Washington State's Model Toxic Control Act sets an upper limit of $10^{-5}$ (ILCR) for Level B cleanups. The limit of $4 \mathrm{mrem} / \mathrm{y}$ for consumption of drinking water containing radionuclides is equivalent to an $\Pi C R$ of $1.2 \mathrm{x}$ $10^{-4}$.

The preferred alternative identified in the draft TWRS-EIS yields a peak risk of $3 \times 10^{-4}$. Thus, the combined risk impacts of the two sources analyzed in the draft TWRSEIS, residual tank waste following retrieval and the 4,000 gal assumed to have leaked from each tank, exceed all regulatory cleanup limits. Previous work performed by Foster Wheeler Environmental indicates that the risks associated with leakage of this magnitude are relatively smail in comparison to the risks associated with $1 \%$ residual waste in the tanks. Therefore, the risks associated with the residual waste in the tanks alone are only somewhat less than $3 \times 10^{4}$. Thus, no leakage from tanks can be allowed unless regulatory limits are raised, unless alternate modeling assumptions are made, unless the level of residual waste in the tanks is reduced, or unless a decision is made that the tanks should be razed and contaminated soil and debris removed.

\subsubsection{Criterion Recommendation}

The effects of alternate modeling assumptions and greater than $99 \%$ cleanup effectiveness should be evaluated against cleanup limits of $10^{-4}$ and $10^{-5} \mathrm{ILCR}$, and a hazard index of 1.0. This evaluation is needed to define conditions that would allow for leakage within acceptable risk constraints, and permit cost-effective closure using backfilling and the Hanford Barrier. 


\author{
WHC-SD-WM-ES-378, Rev 0 \\ (Reference WHC-SD-WM-ES-392. Rev. 0)
}

\title{
3.8 CRITERION 8 - TANK SOURCES OF RISK
}

Establish the risk impacts of other sources, e.g., past leakage into the ground and inso tank concrete, that should be considered in addition to the risk impacts of residual tank waste and new leakage.

\subsubsection{Importance of Criterion}

Consideration of the risks associated with past leakage may be important for establishing allowable leakage thresholds where high leakage or high-risk leakage has occurred in the past, e.g., in T Tank Farm. Neither past leakage nor contaminated concrete was specifically addressed in the draft TWRS-EIS, although it may have been assumed that these sources are included in the $1 \%$ residual waste source following retrieval operations. The combined effect of these two sources on risk is smaller than the effect of $1 \%$ residual waste remaining in the tanks.

\subsubsection{Criterion Recommendation}

The cumulative risk impacts of all tank sources should be considered, especially if alternate modeling assumptions do not significantly reduce apparent risk and/or if relief in regulatory risk limits cannot be considered or granted at this time. This outcome would drive the need to achieve greater retrieval effectiveness (e.g., $0.1 \%$ residual waste in the tanks). The relative contribution of past leakage into the ground and into concrete would then become significant. 


\author{
WHC-SD-WM-ES-378, Rev 0 \\ (Reference WHC-SD-WM-ES-392. Rev. 0)
}

\title{
3.9 CRITERION 9 - LEAKAGE CONCENTRATIONS
}

Determine the methods that should be used to estimate the concentrations of COCs in leakage and the residual tank waste.

\subsubsection{Importance of Criterion}

The concentrations of soluble COCs in the tank liquid, especially ${ }^{99} \mathrm{Tc}$, should be better estimated to determine the risks due to tank leakage and residual tank waste. There is evidence that ${ }^{99} \mathrm{Tc}$, the primary contributor to carcinogenic risk, concentrates in the interstitial liquid that occupies the pore spaces between sludge particles. When an increased hydraulic head of standing sluicing liquid exists in a tank, interstitial liquid may preferentially be driven from the tank through leaks in the tank steel. Improved sluicing methods that would minimize such leakage are under consideration. These methods involve sluicing in the core area of the tank waste in order to retain a layer of waste over holes that may exist in the wall of the tank. When the protective layer of saltcake or sludge on the wall is subsequently removed by sluicing, the concentrations of ${ }^{99} \mathrm{Tc}$ and the other soluble $\mathrm{COCs}$ in the sluicing liquid would be in approximate proportion to their average compositions in the tank.

A small sludge heel is likely to remain when sluicing a tank is completed. The heel material in some tanks has agglomerated and thus, probably has a smaller pore volume than sludge that has not agglomerated. A smaller pore volume would yield a lower fraction of interstitial liquid containing soluble ${ }^{99} \mathrm{Tc}$ and other COCs. However, the sludge particles may contain higher relative amounts of uranium and associated COCs if relatively large particles of undissolved fuel were transferred to the tank. Little information exists on the concentrations of COCs in heels relative to their concentrations in sludge that exists above it.

\subsubsection{Criterion Recommendations}

Average relative concentrations of COCs in sluicing liquid and in sludge should be used until better data are obtained through tank characterization efforts. Concentrations of ${ }^{99} \mathrm{Tc}$ and other COCs proportioned to the saturated concentration of nitrate in interstitial liquid should be used for estimating leakage risks. This approach represents a balance between the higher relative concentrations of ${ }^{99} \mathrm{Tc}$ observed in interstitial liquid and the below-saturated conditions that will probably exist in sluicing waters at the time tank holes are exposed. 
WHC-SD-WM-ES-378, Rev 0

(Reference WHC-SD-WM-ES-392, Rev. 0)

\subsection{CRITERION 10 - ACCEPTABLE CLOSURE OPTIONS}

Identify and establish the acceptability of closure options.

\subsubsection{Importance of Criterion}

There are two basic options for closing tank farms following retrieval of tank wastes: (1) fill the tanks with gravel or grout and cover with a Hanford Banier (Option 1) or (2) raze the tanks, and retrieve and decontaminate tank debris and contaminated soil (Option 2). Foster Wheeler evaluated in situ washing of contaminated soil as a third option (Option 3), but concluded that the technology would be relatively ineffective and costly. Option 1 is preferred for Hanford Site Tank closure because it involves proven and relatively safe technology. Option 2 is feasible, but is likely to be very expensive pose high worker risks.

\subsubsection{Criterion Recommendation}

Option 1, filling the tanks following sluicing and covering with a Hanford Barrier, is the preferred option due to its relatively low cost, low risk to workers, and use of simple, easily implemented technology. Sluicing can probably be augmented with other tank waste retrieval technologies, such as robotic excavation, as necessary to achieve final cleanup objectives and allow implementation of Option $I$ as a compliant alternative. Option 2 should be avoided, wherever possible, by employing optimized sluicing and other effective means to retrieve tank waste and limit leakage. Options 2 or 3 should be exercised only if no other cost-effective supporting technology exists to retrieve waste and limit leakage to levels that would ensure compliance using Option 1. Planning for Options 2 or 3 may be necessary if compliance limits are restrictive and if limits cannot be met with Option 1. 


\author{
WHC-SD-WM-ES-378. Rev 0 \\ (Reference WHC-SD-WM-ES-392. Rev. 0)
}

\title{
3.11 CRITERION 11 - LEAKAGE YOLUAES
}

Establish the best method for quantifying the volumes of past and furure leakage.

\subsubsection{Importance of Criterion}

Past and future leakage are two contributors to cumulative risk. The volumes of leakage are multiplied by the associated concentrations of COCs in the leakage to establish the source terms used for risk modeling. Hanlon 1995 reports 67 tanks have leaked a total of 600,000 to $900,000 \mathrm{gal}$ of liquid waste during past sluicing and waste storage periods.

The amount of new leakage expected during new sluicing operations has been estimated at between 4,000 and 40,000 gal per leaking tank. Past leakage volumes averaged 11,000 gal per leaking tank. Foster Wheeler assumed that $42 \%$ of all tanks would leak, averaging $40,000 \mathrm{gal}$ apiece during new sluicing operations. These assumptions were based on historical tank failure rates and an estimate of potential leakage from Tank 241-C-106 provided by Westinghouse Hanford Company. Average new leakage of 4,000 gal was assumed for each of the tanks in the draft TWRS-EIS. The assumptions made in the draft TWRS-EIS would result in a factor of four lower overall new leakage, compared to the Foster Wheeler analysis. However, most of the cumulative risk is attributable to the $1 \%$ residual tank waste. Thus, the overall effects of the different leakage assumptions are relatively small. However, the overall effects would be substantial if the residual waste goai were reduced to $0.1 \%$.

\subsubsection{Criterion Recommendations}

Actual leakage volumes during sluicing are expected to vary over a fairly wide range depending on tank conditions and the methods of leak detection and mitigation technologies employed. Improved sluicing techniques (i.e., sluicing the core area of the tank first to retain a layer of waste over holes that may exist in the tank wall) should reduce the potential for and quantity of leakage. This benefit may be offset by the effects of tank aging, which may increase rates of leakage due to creation of cracks and holes caused by tank settling and corrosion.

Longer sluicing durations than in the past may also be required due to the presence of thick saltcake layers and the increased potential for agglomeration of sludge particles, both of which would increase the difficulty of sluicing. An increased sluicing time equates to a longer hydraulic head time. The volume of leakage is directiy proportional to both the magnitude of head and the time period of applying the head above a leak. Pending a more rigorous analysis, the average leakage from tanks in the past $(11,000 \mathrm{gal})$ is preliminarily recommended for each tank assumed to leak during new sluicing operations. If reexamination of historical tank failure rates, conditions of individual tanks, and current sluicing schedules continues to support the 11,000 gal leakage volume and the $42 \%$ leakage frequency used by Foster Wheeler, then the average SST leakage would be 4,600 gal. This is similar to the value used in the draft TWRS-EIS. 
WHC-SD-WM-ES-378. Rev 0

(Reference WHC-SD-WM-ES-392, Rev. 0)

\subsection{CRITERION 12 - ALIGNED WASTE SOURCES}

Establish whether the impacts of upgradient and downgradient groundwater contanination should be included in risk estimates.

\subsubsection{Importance of Criterion}

Two or more tank farms and other types of waste sites often will be aligned with future groundwater flow directions. The maximally exposed onsite farmer will be subjected to risks from overlapping plumes produced by aligned sources. Appropriate limits for protecting the health of the farmer from the cumulative effects of overlapping plumes need to be defined.

\subsubsection{Criterion Recommendation}

Cumulative risks from all aligned sources should be less than $1.2 \times 10^{-4}$ ILCR through the drinking water pathway (equivalent to $4 \mathrm{mrem} / \mathrm{y}$ ) and less than 1.0 hazard index (including not exceeding the MCL for nitrate). These values are based on regulatory limits for protecting drinking water. 


\author{
WHC-SD-WM-ES-378, Rev 0 \\ (Reference WHC-SD-WM-ES-392, Rev. 0)
}

\title{
3.13 CRITERION 13 - RISK APPORTIONMENT
}

Deternine the apportionment of allowable cumulative risk among the contributing sources when no or more plumes will overlap.

\subsubsection{Importance of Issue}

Without careful planning and analysis, a potential exists for conducting cleanup actions that are not cost-effective. It may be cheaper, for example, to retrieve extra tank waste than to prevent leakage of equivalent risk, or vice versa. Also, two waste sources, one with and one without the Hanford Barrier, are unlikely to produce significantly overlapping plumes, even when they are aligned. In this event, the period of groundwater contamination in the no-barrier case would be completed well before the first contamination occurs in the barrier case.

\subsubsection{Criterion Recommendation}

If safe groundwater conditions can be assured, the mobile COCs in low-risk sites such as certain cribs and trenches should be allowed to be flushed naturally to the groundwater at the higher recharge rates that occur when no closure barrier is used. This approach avoids the costs of Hanford Barriers for some of the waste sources and creates more flexibility for accommodating the risks associated with aligned sources. The levels of risk reduction required for each of the remaining aligned sources should be based on the alternative that provides for the most cost-effective remediation and closure of all of the aligned sources as a system. Costs in the cost-effectiveness calculation should include all life-cycle costs.

Effectiveness should be based primarily on cleanup effectiveness but should be tempered with consideration of worker safety and technical feasibility. Incremental cost-effectiveness analyses should be made to determine if later stages of cleanup action are worthwhile.

Thus, evaluating the aligned sources as a system is recommended to enable definition of the appropriate remedial actions and residual risks for each source. Several iterations may be necessary to identify the most cost-effective cleanup actions that are expected to yield cumulative risks that are in compliance with closure plan limits. 


\author{
WHC-SD-WM-ES-378, Rev 0 \\ (Reference WHC-SD-WM-ES-392, Rev. 0)
}

\title{
3.14 CRITERION 14 - LEAKAGE DETECTION TECHNOLOGY
}

Determine the impact of leakage detection and response technology on reducing the amount of new leakage that may occur during sluicing.

\subsubsection{Importance of Criterion}

Currently available leakage detection technology consists of sensitive liquid level measuring devices, flow meters, and visual estimates of remaining solid waste in the tank at various intervals during the tank sluicing cycle. Foster Wheeler estimated the sensitivity of leakage detection by this method at between 6,000 and 20,000 gal after establishing the base sluicing conditions. The establishment of base conditions includes adding sufficient water to replace liquid removed by previous salt well pumping and immerse the intake of the new slurry pump. On average, an addition of about $140,000 \mathrm{gal}$ of water may be required to establish these base conditions before initiating sluicing. Detection of leakage with currently available technology is not possible when base conditions are being established. A potentially promising leakage detection alternative, electric resistance tomography (ERT) may be capable of detecting a 1,000- to 8,000 -gal leak during sluicing as well as during establishment of base conditions. However, the ERT technology is not proven at this time.

After detection of a leak by any method, leakage will continue until the drainable liquid level is pumped down to a level below the level of the leak. Salt well pumping may be required to augment the sluice liquid recovery pump when a leak is suspected on the bottom of a tank or low on the tank's wall. The time required to draw down the drainable liquid level in a tank may be days or weeks depending on the permeability of the waste. A one-day response time for draining a tank may result in 40 to 2,400 gal of additional leakage, based on the range of historic leakage rate data. A two-week response time may result in 600 to $34,000 \mathrm{gal}$ of additional leakage. Thus, for the response times considered, the total leakage that may occur before and after detection may range from about 6,000 to 54,000 gal with currently available technology, and from about 1,000 to 47,000 gal with the unproven ERT technology. Leakage of these levels may have significant impacts on risk in certain tanks. Only a fraction of the tanks are expected to leak during sluicing, however, and a high percentage of the leaking tanks are expected to leak at upper elevations on the tank wall where the amount of leakage will be minimized.

\subsubsection{Criterion Recommendation}

The range and maximum levels of leakage that may occur before and after leakage detection are high. However, the probability of a large amount of leakage is low due to the expected benefits of core sluicing, the low incidence of large amounts of leakage in the past, and the use of leakage detection technology. The use of ERT technology, if and when it is proven, may reduce the magnitude of leakage by providing earlier detection when the tank is being filled to establish base sluicing conditions. The effectiveness of salt weil pumping as a leakage response action should be better quantified. 


\subsection{CRITERION 15 - LEAKAGE MITIGATION TECHNOLOGY}

Determine which leakage mitigation technologies are viable and how much impact will they have on reducing leakage.

\subsubsection{Importance of Criterion}

Various methods of mitigating leakage are available and have potential to limit the risks associated with leakage. These methods include using subsurface barriers, sluicing with liquids containing entrained sludge particles, sluicing the core area of the tank first, and using salt well pumping to reduce the heal of liquid in the leaking tank. Foster Wheeler evaluated subsurface barrier technologies as a means of containing leakage from tanks, and concluded that all of the technologies evaluated would pose significant technical and worker safety risks and exhibit low cost-effectiveness in general-use applications. Foster Wheeler also proposed limiting the sludge settling time in the sluicing receiver tank in order to entrain the slowest settling sludge particles in the sluicing stream as a means of plugging small leaks with particles. Sluicing the core area of the tank first in order to retain a layer of waste as a seal over leaks that may exist in the wall of the tank was proposed in the draft Single-Shell Tank Closure Work Plan (WHC 1994). Salt-well pumping is a proven technology for minimizing the level of drainable liquid in a tank, and could be used following detection of leakage.

\subsubsection{Criterion Recommendations}

Cost-effective leakage mitigation technologies should be used to limit leakage to the minimum practicable achievable level. Subsurface barriers do not appear to be cost-effective in general-use applications, but may prove to be useful for limiting leakage from tanks that have experienced high leakage rates. Sluicing the core of the tank waste first is recommended as part of the tank waste retrieval baseline. Using entrained fine sludge particles in the sluicing stream may be effective, especially during the later stages of sluicing when most of the easily suspended finer particles have been removed from the tank, leaving coarser, highly permeable sludge to be removed. Salt-well pumping should be used where feasible following detection of leakage. 


\author{
WHC-SD-WM-ES-378, Rev 0 \\ (Reference WHC-SD-WM-ES-392. Rev. 0)
}

\title{
3.16 CRITERION 16 - INDIVIDUAL TANK CHARACTERISTICS
}

Consider the design and physical characteristics of individual tanks when defining allowable leakage.

\subsubsection{Importance of Criterion}

Hanford Site tanks vary significantly in design, physical integrity, and characteristics of the waste they contain. The capacities of the tanks range from 50,000 to $1,000,000$ gal. Some tanks are highly congested with failed pumps, sluicers, air-lift circulators, and instrumentation; the head space in other tanks is highly restricted. Some tanks have several available pump and sluicer pits, whereas some have none. Some tank farms are cluttered with essential service and monitoring equipment. The tanks contain varying quantities of waste exhibiting different retrieval difficulties. Some tanks have leaked in the past, and some contain potentially flammable and explosive materials. All of these factors may restrict the ability to use specific waste retrieval, leakage detection, and leakage mitigation technologies in individual tanks or tank farms. These factors may also impact the rate of sluicing and head of sluicing liquid in the tanks. Thus, design and operating latitudes and constraints are likely to be imposed for individual tanks to ensure safe and efficient retrieval operations. These latitudes and constraints may directly impact the allowable leakage from those tanks.

\subsubsection{Criterion Recommendation}

Allowable leakage for individual tanks should be based in part on estimates of the probabilities and amounts of leakage derived from evaluation of (1) the specific characteristics of the tanks and (2) the retrieval, leakage detection, and leakage mitigation technologies likely to be best suited to individual tank characteristics. This will provide a basis for a balanced, cost-effective approach to the design and operation of waste retrieval and LDMM equipment. 


\subsection{CRITERION 17 - EXCEEDANCE OF ALLOWABLE LEAKAGE VALUES}

Determine the consequences of exceeding an allowable leakage value.

\subsubsection{Importance of Criterion}

Exceeding an allowable leakage value can be accommodated by reducing the allowable leakage values of other aligned waste sources. It can also be accommodated by increasing the tank's cleanout objective from $99 \%$ to $99.5 \%$, for example, or allocating higher cleanup objectives among several aligned tanks.

\subsubsection{Criterion Recommendation}

Authority should be granted to exceed an allowable leakage value up to a predetermined ceiling. Retrieval operations should be allowed to continue to the ceiling level. An exceedance of the allowable leakage value up to the ceiling level should be accommodated by modifying the cleanup objectives of other aligned sources. Similarly, achieving a degree of leakage below the allowable leakage value can increase flexibility, e.g., by enabling higher allowable leakage values in other aligned tanks. Immediate cessation of sluicing operations should be required when a leakage ceiling is exceeded. Reevaluation of waste retrieval plans should then occur. Revised plans may dictate the use of dry retrieval methods to prevent any additional leakage, or razing the tanks and exhuming contaminated debris and soils. 


\subsection{CRITERION 18 - EXCEEDANCE OF LEAKAGE CEILINGS}

Establish whether sluicing should be allowed when there is a likelihood of exceeding a leakage ceiling.

\subsubsection{Importance of Criterion}

Previous analyses conducted by Boomer et al. (1994) and Foster Wheeler indicated that alternate tank waste retrieval options, including dry and semi-dry retrieval options pose high costs and worker risks. Very high costs and worker risks were attributed to tank razing and debris/soil excavation and treatment.

\subsubsection{Criterion Recommendation}

Plans should be made to maximize use of sluicing with the ultimate objective of achieving compliance with the requirements of the closure plan. Dry or semi-dry retrieval should be planned as the first contingency if leakage ceilings are exceeded. Razing the tanks and excavating the contaminated debris and soil should be considered the last resort. 


\author{
WHC-SD-WM-ES-378, Rev 0 \\ (Reference WHC-SD-WM-ES-392. Rev. 0)
}

\title{
3.19 CRITERION 19 - ABSOLUTE LIMTT ON ALLOWABLE LEAKAGE \\ Establish whether an absolute limit should be imposed on the amount of leakage allowable to ensure protection of the groundwater.
}

\subsubsection{Importance of Criterion}

A very high level of leakage could conceivably penetrate to and contaminate the groundwater. The highly drained nature of Hanford Site soils creates a sponge-like effect that would significantly retard the flow of leaked liquid waste to the water table. Preliminary calculations performed by Foster Wheeler indicate that at least 200,000 gal of leakage below individual tanks would be bound in the soil well above the water table. The water would travel vertically toward the water table at sufficiently low rates to allow excavation of the contaminated soil, if necessary. Another evaluation performed by Foster Wheeler indicated that up to 480,000 gal of liquid could leak from a Tank 241-A-101, including the water added to the tank to create base conditions before initiating sluicing. A maximum of 140,000 gal could leak in the typical case based on average drainable liquid data and volumes of water required to submerge the head of the slurry removal pump. Thus, maximum levels of leakage from individual tanks would not pose environmental threats in most cases if excavation and treatment of the soil, or a similarly effective technology is planned as a mitigating action.

\subsubsection{Criterion Recommendation}

Individual tank conditions and soil conditions at the tank farm should be used to model the spread of the maximum potential leakage to verify that the leakage can be dealt with within the limits of feasibility of available mitigation technologies. The probability of maximum leakage should also be considered before imposing an absolute limit on allowable leakage. 


\author{
WHC-SD-WM-ES-378, Rev 0 \\ (Reference WHC-SD-WM-ES-392, Rev, 0)
}

\title{
4.0 EXAMPLE PROCESS FOR DERIVING ALLOWABLE LEAKAGE VALUES
}

Criteria established in Section 3 were used, with a few noted exceptions, to derive allowable leakage values for a hypothetical tank farm containing six tanks. The process used to develop preliminary allowable leakage values is described in the order of the criteria previously presented. The process used to adjust allowable leakage values during a sequenced hypothetical cleanup of the six tanks is also described.

\subsection{PRELIMINARY ALLOWABLE LEAKAGE VALUES}

The preliminary allowable leakage values are calculated for this hypothetical case to support retrieval planning decisions and establish the operational leakage limit for the first tank retrieved. The final criteria used to establish the preliminary allowable leakage values are shown below.

- Criterion 1 - The maximally exposed onsite residential farmer scenario was used as the controlling risk basis.

- Criterion 2 - The Multimedia Environmental Pollutant Assessment System was used to model the risk scenario. Typical Hanford Site environmental modeling conditions and input data were used. The model conditions and input data are similar to those used in the draft TWRS-EIS.

- $\quad$ Criterion 3 - The point of compliance was assumed to be immediately downgradient of the tank farm.

- Criterion 4 - Compliance risks were modeled over a 30,000-year period.

- Criterion 5 - The primary COCs evaluated were ${ }^{99} \mathrm{Tc}$, ${ }^{129} \mathrm{I},{ }^{14} \mathrm{C}$, uranium, and nitrate.

- Criterion 6 - The flux from the tank farm was assumed to be released into a vadose zone cell with surface dimensions equal to that of the tank farm.

- $\quad$ Criterion 7 - The allowable incremental lifetime cancer risk was assumed to be $10^{-4}$ in one case and $10^{-5}$ in a second case.

- Criterion 8 - The risk impacts of past leakage and waste contaminated concrete were considered in addition to the risk impacts associated with residual waste in the tank and new leakage.

- Criterion 9 - The concentrations of COCs were based on the assumptions made in Functions and Requirements for Hanford Single Shell Tank Leakage Detection and Monitoring (Cruse et al. 1995). These assumptions are somewhat conservative compared to the recommended approach. 


\section{WHC-SD-WM-ES-378, Rev 0 \\ (Reference WHC-SD-WM-ES-392, Rev. 0)}

- Criterion 10 - The selected closure approach was backfilling the tanks with gravel following nominal retrieval of $99 \%$ of the waste and capping with a Hanford Barrier.

- Criterion 11 - The volume of assumed leakage in the tank farm in the past was 285,000 gal based on historical data.

- Criterion 12 - No other tank farms or waste sites that contribute COCs were assumed aligned with the hypothetical tank farm. Carcinogenic risk limits assumed for the single tank farm were $10^{-4}$ and $10^{-5}$ as in Criterion 7 .

- Criterion 13 - There was no need to divide risk limits between other aligned farms and contributing waste sites.

- Criteria 14 and 15 - Currently available leakage detection and mitigation technology were assumed to be able to limit total new leakage in the tank farm to a maximum of $60,000 \mathrm{gal}$.

- Criterion 16 - The design and physical characteristics of the tanks in the farm were assumed not to restrict the use of sluicing and the application of currently available leakage detection and mitigation technologies.

- Criterion 17 - Modeling showed that the planned actions for the tank farm could not satisfy the $10^{-5}$ risk limit. More efficient sluicing would be required to accommodate a reasonable level of leakage and comply with the $10^{-5}$ risk limit. However, the planned actions would satisfy the $10^{-4}$ risk limit.

- Criterion 18 - Dry and semi-dry retrieval methods were planned as possible contingencies.

- Criterion 19 - The tank and soil conditions indicated that the maximum potential leakage would penetrate to a depth that could be accessed using current excavation technology. Thus, no absolute limit on leakage was established.

Based on application of the criteria, the preliminary allowable leakage values shown in Table 4-1 were determined. As can be seen, the soil capacity (Tier 1) exceeds the maximum potential leak (Tier 2) in all cases. Additionally, the preliminary allowable leakage values (Tier 3 ) are all large enough to be above the leakage detection limit of 6,000 to $20,000 \mathrm{gal}$. On the basis of this planning exercise, it was assumed that remediation of the tank farm using sluicing was authorized and to be conducted under the $10^{-4}$ risk limit. 


$$
\begin{gathered}
\text { WHC-SD-WM-ES-378. Rev } 0 \\
\text { (Reference WHC-SD-WM-ES-392. Rev. 0) }
\end{gathered}
$$

Table 41. Hypothetical Preliminary Allowable Leakage Criteria.

\begin{tabular}{|c|c|c|c|}
\hline Tank & Tier 1 (gal) & Tier 2 (gal) & Tier 3 (gal) \\
\hline \hline 1 & 200,000 & 180,000 & 46,000 \\
\hline 2 & 200,000 & 77,000 & 38,000 \\
\hline 3 & 200,000 & 90,000 & 66,000 \\
\hline 4 & 200,000 & 68,000 & 38,000 \\
\hline 5 & 200,000 & 67,000 & 100,000 \\
\hline 6 & 200,000 & 74,000 & 80,000 \\
\hline
\end{tabular}

\subsection{ADJUSTED ALLOWABLE LEAKAGE VALUES}

The following is a hypothetical example of how the preliminary allowable leakage values would be applied and updated as retrieval of each of the tanks in the tank farm was concluded.

When the first tank was sluiced, the operations personnel were granted an operational leakage limit of $46,000 \mathrm{gal}$ (the Tier 3 allowable leakage value). During retrieval of this tank no leakage was detected and the $99 \%$ retrieval objective for the tank was met. A smail level of leakage $(3,000 \mathrm{gal})$ was attributed to the tank, however, as a function of the probability for and volume of the average nondetectable leakage. The difference between the allowed volume of leakage and the assumed nondetectable leakage was converted to a risk credit. This risk credit was evenly apportioned to the remaining tanks in terms of additional allowable leakage volume. An updated operational leakage limit was established for the second tank of 45,000 gal based on this additional risk credit. No leakage was detected when the second tank was successfully sluiced. The same risk credit was again distributed to the remaining tanks in terms of increased allowable leakage volumes.

The third tank was also sluiced without detectable leakage, but only $98 \%$ of the waste was retrieved rather than the goal of $99 \%$. Because no leakage was observed, the tank farm was debited for the risk associated with the assumed 3,000 gal nondetectable leak. The risk associated with the shortfall in waste retrieval was then subtracted from the remaining risk allowance for leakage from the three tanks that had not yet been sluiced. The difference was evenly divided between the three tanks. This resulted in reducing the original allowable leakage values assigned to the tanks to a small fraction of their original levels.

The fourth and fifth tanks were sluiced, and although retrieval goals were met, the tanks leaked above their reduced allowable leakage values, consuming the leakage risk allocation associated with leakage from the sixth tank. The sixth tank had been scheduled as the last tank in the farm to be retrieved because the integrity of the tank was suspect. Had sufficient leakage and/or residual waste risk credit been built up during cleanout of the first five tanks, the sixth tank would have been sluiced. Thus the sixth tank was cleaned out instead using a dry retrieval method. The tank farm was then closed by backfilling each tank 
WHC-SD-WM-ES-378. Rev 0

(Reference WHC-SD-WM-ES-392, Rev. 0)

with gravel and capping the farm with a Hanford Barrier to achieve a predicted cumulative ICLR of $9 \times 19^{-5}$. 
WHC-SD-WM-ES-378, Rev 0

(Reference WHC-SD-WM-ES-392. Rev. 0)

\subsection{SUMMARY OF CRITERIA RECOMMENDATIONS REQUIRING APPROVAL}

A summary of the allowable leakage criteria recommendations requiring approval is provided in Table 5-1.

Table 5-1. Summary of Criteria Recommendations.

\begin{tabular}{|c|c|c|}
\hline Number & $\begin{array}{l}\text { Allowable Leakage } \\
\text { Criteria }\end{array}$ & Recommendations \\
\hline 1 & Controlling Risk Scenario & $\begin{array}{l}\text { - Maximally Exposed Individual } \\
\text { - Groundwater use pathway } \\
\text { - Onsite farmer } \\
\text { - Consistent with TWRS-EIS }\end{array}$ \\
\hline 2 & Risk Models and Data & $\begin{array}{l}\text { - One-dimensional release algorithms and transport } \\
\text { models } \\
\text { - Consistent with TWRS-EIS }\end{array}$ \\
\hline 3 & Point of Compliance & $\begin{array}{l}\text { - Several compliance points for sensitivity } \\
\text { - Based on future land use planning } \\
\end{array}$ \\
\hline 4 & Duration of Compliance & - Establish effectiveness of Hanford Surface Barrier \\
\hline 5 & Constituents of Concern & - ${ }^{99} \mathrm{Tc},{ }^{129} \mathrm{I},{ }^{14} \mathrm{C}$, uranium, and nitrate \\
\hline 6 & $\begin{array}{l}\text { Vadose Zone Flux } \\
\text { Distribution }\end{array}$ & - Consistent with points of compliance \\
\hline 7 & Allowable Risk & $\begin{array}{l}\text { - } 10^{-4} \text { or } 10^{-5} \text { incremental lifetime cancer risk } \\
\text { - Hazard index of } 1.0\end{array}$ \\
\hline 8 & Tank Sources of Risk & $\begin{array}{l}\text { - Cumulative risk impacts of all tank sources should } \\
\text { be considered }\end{array}$ \\
\hline 9 & Leakage Concentrations & $\begin{array}{l}\text { - Use average relative concentrations of COCs in } \\
\text { sluicing liquid and in sludge }\end{array}$ \\
\hline 10 & $\begin{array}{l}\text { Acceptable Closure } \\
\text { Options }\end{array}$ & $\begin{array}{l}\text { - Assume the tanks are filled with gravel or grout and } \\
\text { covered with a Hanford Barrier following waste } \\
\text { retrieval as the preferred option } \\
\text { - Plan for tank razing and soil excavation or in situ } \\
\text { soil washing as contingency }\end{array}$ \\
\hline 11 & Leakage Volumes & $\begin{array}{l}\text { - Initially assume the historical average of } 11,000 \mathrm{gal} \\
\text { - Perform a more rigorous analysis }\end{array}$ \\
\hline 12 & Aligned Waste Sources & $\begin{array}{l}\text { - Exclude unimportant sources that will not be capped } \\
\text { - All other aligned waste sources should be considered } \\
\text { in calculation of cumulative risk }\end{array}$ \\
\hline
\end{tabular}


WHC-SD-WM-ES-378, Rev 0

(Reference WHC-SD-WM-ES-392, Rev, 0)

\begin{tabular}{|c|c|c|}
\hline Number & $\begin{array}{l}\text { Allowable Leakage } \\
\text { Criteria }\end{array}$ & Recommendations \\
\hline 13 & Risk Apportionment & $\begin{array}{l}\text { Don't cover low-risk sites (such as some cribs and } \\
\text { trenches) where safe groundwater conditions can be } \\
\text { ensured } \\
\text { - Evaluate risk reduction levels based on cost- } \\
\text { effectiveness of feasible options for entire system }\end{array}$ \\
\hline 14 & $\begin{array}{l}\text { Leakage Detection } \\
\text { Technology }\end{array}$ & $\begin{array}{l}\text { - The current baseline detection technology is adequate } \\
\text { to support retrieval } \\
\text { - The use of ERT technology, if proven, should } \\
\text { provide earlier leak detection }\end{array}$ \\
\hline 15 & $\begin{array}{l}\text { Leakage Mitigation } \\
\text { Technology }\end{array}$ & $\begin{array}{l}\text { - Sluice the core of the tank waste first } \\
\text { - Salt-well pumping should be used where practical } \\
\text { following leak detection } \\
\text { - Use of entrained fine sludge particles may prove } \\
\text { effective } \\
\text { - Subsurface barriers generally are not cost-effective }\end{array}$ \\
\hline 16 & $\begin{array}{l}\text { Individual Tank } \\
\text { Characteristics }\end{array}$ & $\begin{array}{l}\text { - Base allowable leakage in part on tank design, } \\
\text { physical integrity, and waste characteristics }\end{array}$ \\
\hline 17 & $\begin{array}{l}\text { Exceedance of Allowable } \\
\text { Leakage Values }\end{array}$ & $\begin{array}{l}\text { - Authority should be granted to exceed an allowable } \\
\text { leakage value up to a predetermined cap }\end{array}$ \\
\hline 18 & $\begin{array}{l}\text { Exceedance of Leakage } \\
\text { Ceilings }\end{array}$ & $\begin{array}{l}\text { - Maximize use of sluicing } \\
\text { - Plan as a first contingency, use of dry or semi-dry } \\
\text { retrieval } \\
\text { - Tank razing and soil excavation should be a last } \\
\text { resort }\end{array}$ \\
\hline 19 & $\begin{array}{l}\text { Absolute Limit on } \\
\text { Allowable Leakage }\end{array}$ & $\begin{array}{l}\text { - Use tank-specific models to verify that the maximum } \\
\text { potential leakage (Tier 2) can be dealt with within } \\
\text { the limits of available mitigation technology }\end{array}$ \\
\hline
\end{tabular}




\subsection{REFERENCES}

Boomer, K.D., S.K. Baker, A.L. Boldt, J.D. Galbraith, J.S. Garfield, C.E. Golberg, B.A. Higley, L.J. Johnson, M.J. Kupfer, R.M. Marusich, R.J. Parazin, A.N. Praga, G.W. Reddick, J.A. Reddick, E.J. Slaathaug, L.M. Swanson, T.L. Waldo, and C.E. Worcester, 1994, Tark Waste Technical Options, WHC-EP-0616, Rev. 1, Westinghouse Hanford Company, Richland, Washington.

Cruse, J.M., D.F. Iwatate, K.S. Tollefson, R.L. Treat, T.L. Trenkler, R.E. Lewis, 1995, Functions and Requirements for Hanford Single-Shell Tank Leakage Detection and Monitoring, WHC-SD-WM-FRD-021, Rev. 0, Westinghouse Hanford Company, Richland, Washington.

Hanlon, B.M., 1995, Waste Status Summary Report for the Month Ending October 31, 1995, WHC-EP-0182-91, Westinghouse Hanford Company, Richland, Washington.

WHC, 1994, Single-Shell Tank Closure Work Plon, DOE/RL-89-16, Rev. A, Westinghouse Hanford Company, Richland, Washington. 
WHC-SD-WM-ES-378, Rev 0

(Reference WHC-SD-WM-ES-392, Rev. 0)

This page intentionaily left blank.

C6-2 


\section{DISTRIBUTION SHEET}

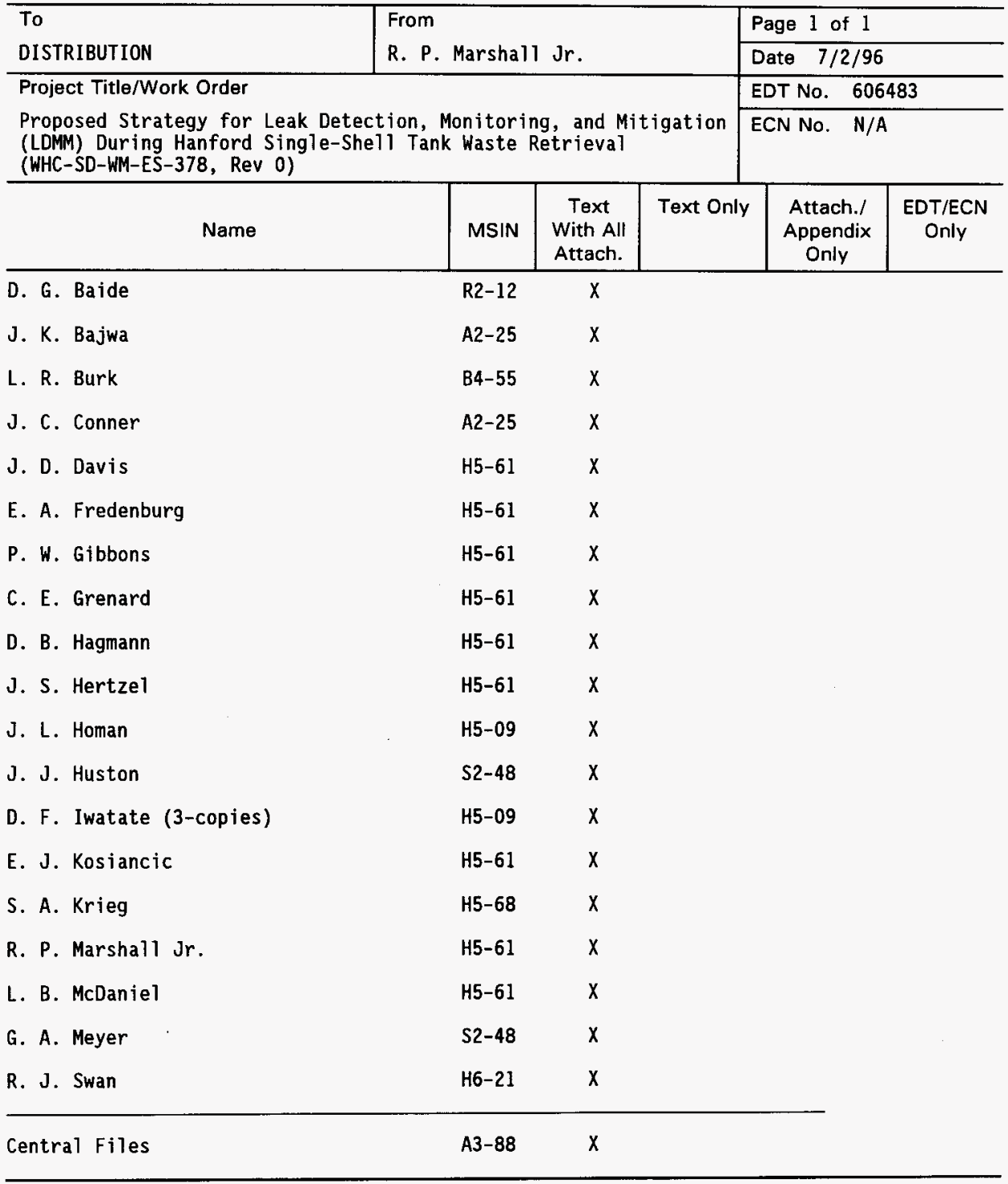

